\title{
DATA REVIEW \\ OF THE HOT DRY ROCK PROJECT \\ AT FENTON HILL, NEW MEXICO
}

\author{
for \\ Office of Geothermal Technologies \\ United States Department of Energy \\ Washington, DC \\ by \\ GeothermEx, Inc. \\ 5221 Central Avenue, Suite 201 \\ Richmond, CA 94804 \\ (510) 527-9876 \\ Under Subcontract to \\ Princeton Economic Research, Inc. \\ 1700 Rockville Pike, Suite 550 \\ Rockville, MD \\ (301) 468-8442
}

DOE Contract DE-AM07-97ID13517

December 1998 


\section{DISCLAIMER}

This report was prepared as an account of work sponsored by an agency of the United States Government. Neither the United States Government nor any agency Thereof, nor any of their employees, makes any warranty, express or implied, or assumes any legal liability or responsibility for the accuracy, completeness, or usefulness of any information, apparatus, product, or process disclosed, or represents that its use would not infringe privately owned rights. Reference herein to any specific commercial product, process, or service by trade name, trademark, manufacturer, or otherwise does not necessarily constitute or imply its endorsement, recommendation, or favoring by the United States Government or any agency thereof. The views and opinions of authors expressed herein do not necessarily state or reflect those of the United States Government or any agency thereof. 


\section{DISCLAIMER}

Portions of this document may be illegible in electronic image products. Images are produced from the best available original document. 


\section{CONTENTS}

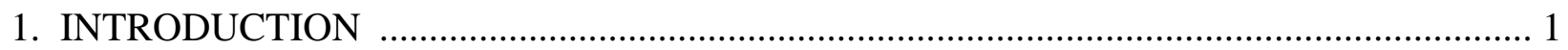

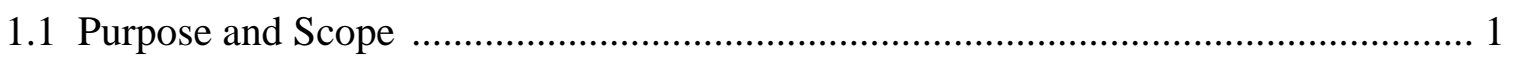

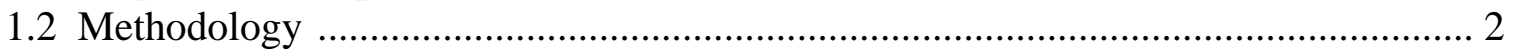

1.3 General Comments on Data Storage, Retrieval and Utility ..................................... 2

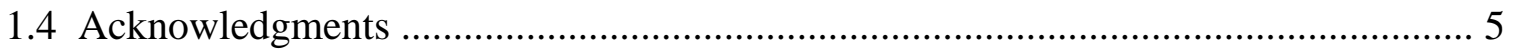

2. HYDRAULIC FRACTURING AND WELL PRESSURIZATION DATA ......................... 6

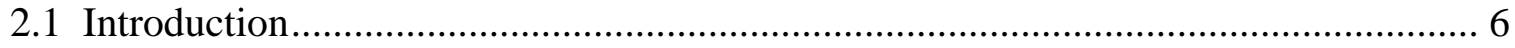

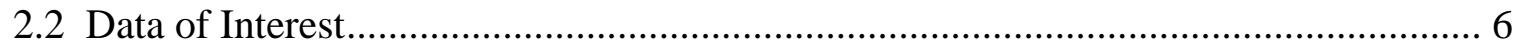

2.3 Experiments of Interest and Location of Data ..................................................... 7

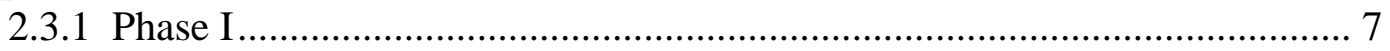

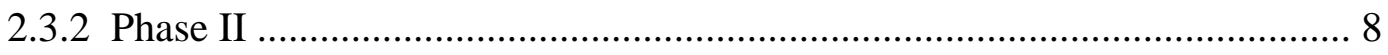

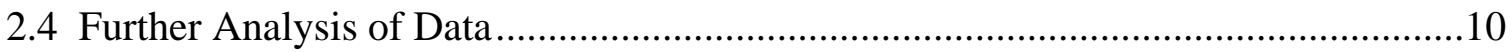

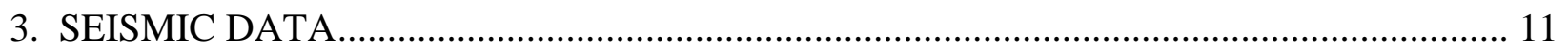

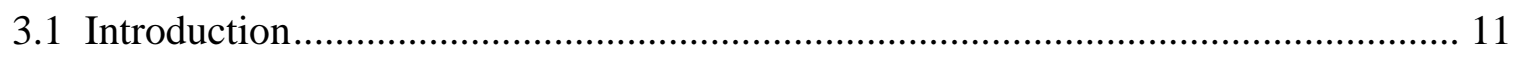

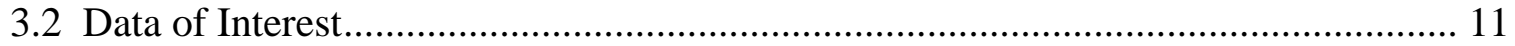

3.3 Experiments of Interest and Location of Data ................................................. 12

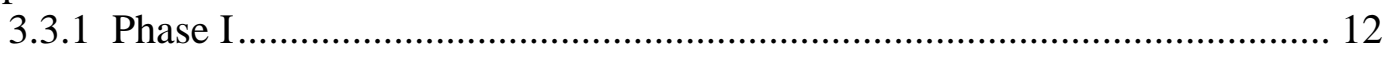

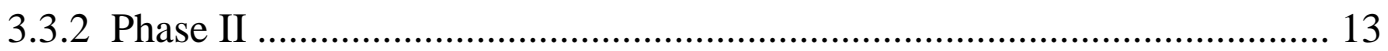

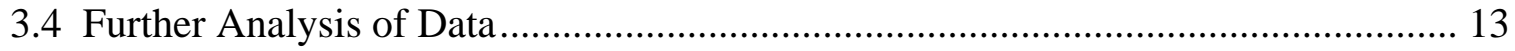

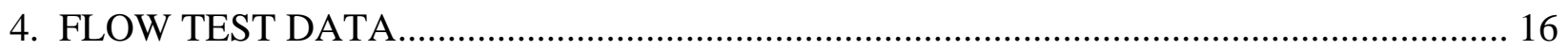

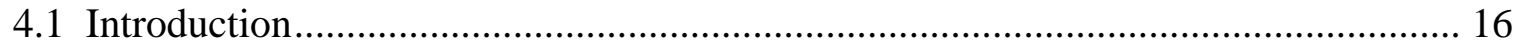

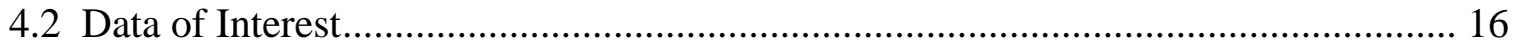

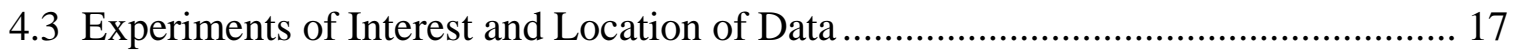

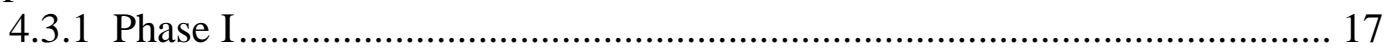

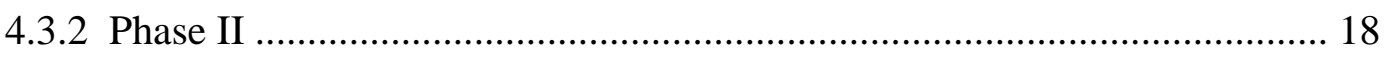

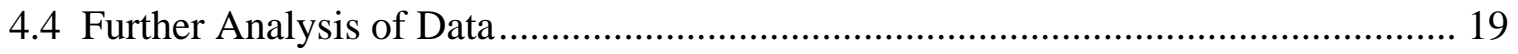

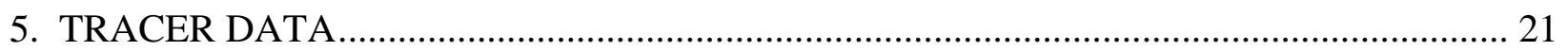

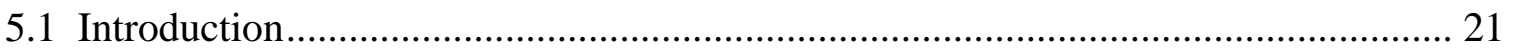

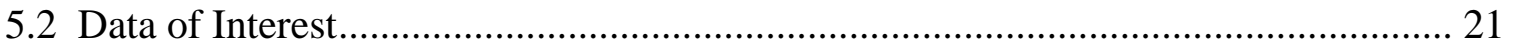

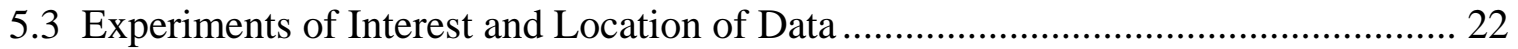

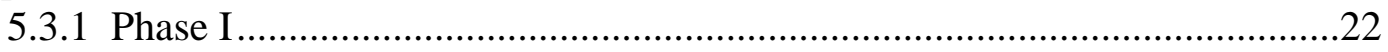

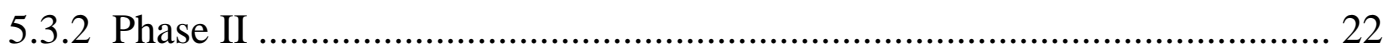

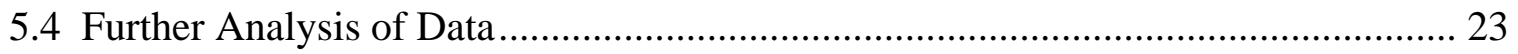




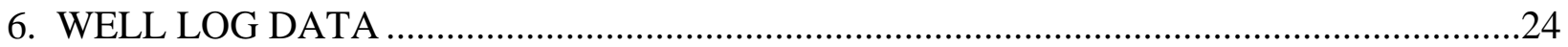

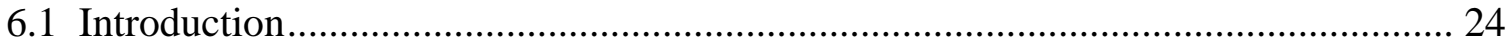

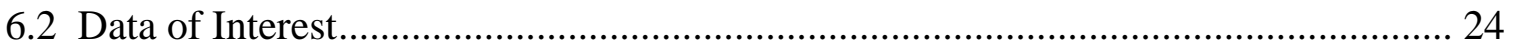

6.3 Experiments of Interest and Location of Data ........................................................... 25

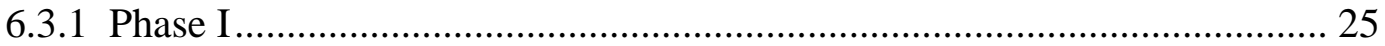

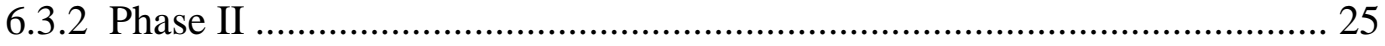

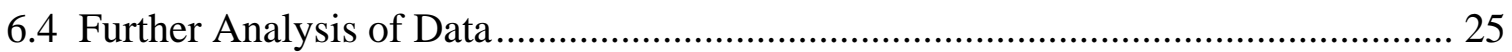

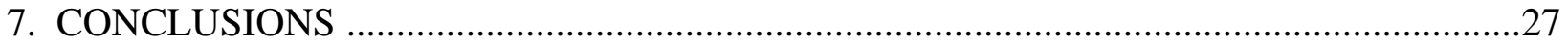

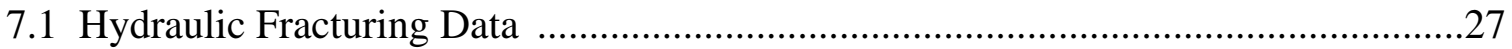

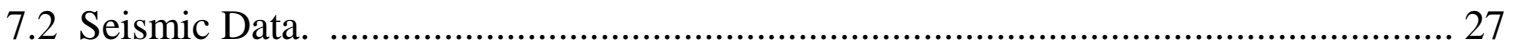

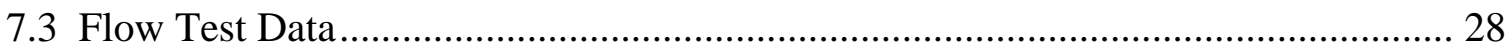

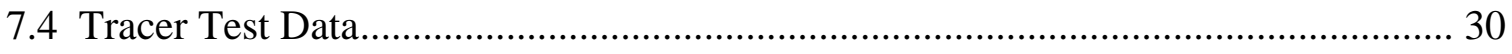

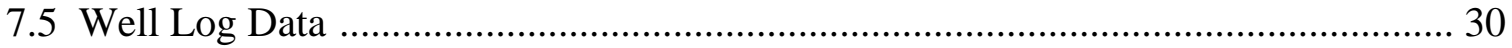

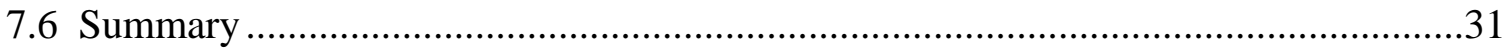

\section{TABLES}

Table 1.1 Summary of Important Experiments, Fenton Hill Hot Dry Rock Project. 


\section{INTRODUCTION}

\subsection{Purpose and Scope}

GeothermEx, Inc. (GeothermEx) is a subcontractor to Princeton Economic Research, Inc. (PERI) on the U.S. Department of Energy's Enhanced Geothermal Systems initiative (contract number DE-AM07-97ID13517). The mandate of PERI's contract with DOE is to transfer, to the geothermal industry and other interested stakeholders, the body of knowledge developed from the more than 20-year-long Fenton Hill Hot Dry Rock project undertaken by Los Alamos National Laboratory (LANL) and its predecessor Los Alamos Scientific Laboratory (LASL). (For simplicity, we use the acronym LANL herein to refer to both organizations.) In keeping with this mandate, one of the task orders under this contract is a review of the Fenton Hill database.

GeothermEx has prepared a separate review of the Fenton Hill project that identifies the primary lessons learned and techniques developed, and summarizes the degree to which these technologies have been transferred to the U.S. geothermal industry; this is referred to as the Peer Review." The current study is referred to as the Data Review," and it concentrates on the data generated by the Fenton Hill project.

The purpose of conducting the Data Review is to identify the important data sets from the Fenton Hill project, to determine where and how these data are stored, and to determine if, in GeothermEx's opinion, further evaluation of the data would be likely to yield additional information valuable to the geothermal industry or to the further development of Enhanced Geothermal Systems (EGS). EGS is a term used to describe the continuum of geothermal resources which, because of low natural permeability or fluid content, require enhancement to render them commercially viable. Hot Dry Rock (HDR) represents the lower end of this continuum of permeability and fluid content.

In the last section of each of Chapters 2 through 6, we discuss possible further analyses of the data that could be undertaken. In Chapter 7, we suggest priorities among these possibilities, keeping in mind the likelihood that further analysis would be of use to future developers of EGS reservoirs.

At the onset of the work, it was anticipated that five main categories of data would be evaluated: 1) geologic data; 2) flow test data; 3) reservoir modeling data; 4) chemical tracer data; and 5) seismic data. Emphasis was to be placed on the data collected during Phase II of the project (when the deeper reservoir was developed; see the Peer Review report for more details), as it was likely that these data would be available in digital form, and thus more amenable to further evaluation (if warranted) than the earlier Phase I data. However, the Phase I data were to be evaluated to a lesser degree by looking at technical memoranda and reports.

It is envisaged that the data thus identified may be evaluated further by interested parties. In addition, PERI has a separate task order to index and archive the data sets of interest so that they are preserved for future developers of EGS. 


\subsection{Methodology}

The Peer Review has been used as a starting point for the Data Review. In the process of doing the Peer Review, we first obtained and reviewed published documents to familiarize ourselves with the Fenton Hill project. Then we met and interviewed many people from LANL who had been involved in doing the work, and obtained and evaluated more documents that presented some of the more significant results. We learned what had been done, and from this we were able to identify the most important experiments (table 1.1) and what kind of information would have been typically generated from each. A list of these experiments and the data sought from each were then provided to present and former LANL staff, and a second visit was made to Los Alamos to specifically discuss the state of the data.

With the advantage of: 1) hindsight from the Peer Review; 2) a new appreciation of what it takes to develop an HDR reservoir; and 3) what information from the Fenton Hill project might be useful in developing the entire spectrum of EGS, we realized that the provisional five categories of data (mentioned in section 1.1) needed to be modified. Therefore, to begin our search for information, we classified the Fenton Hill data more logically into the following categories: 1) hydraulic fracturing data; 2) seismic data; 3) flow test data; 4) tracer test data; and 5) well log data.

While geologic information is fundamental to any geothermal project, its importance at Fenton Hill is its relationship to hydraulic fracturing and well log response. Therefore, in the revised scheme, geologic information is included indirectly in some of the five categories of data mentioned above. Furthermore, because it is site specific, geologic data from Fenton Hill was considered to less useful to the development of other EGS reservoirs.

Reservoir modeling data was eliminated as a separate category because the data used as input to reservoir modeling is essentially well logs, well test data and tracer test data, which are already covered in the other categories of important data. Furthermore, the input data deck from a specific run of a specific numerical model would be useless without the version of the simulator that was used. We discussed modeling with LANL staff, and some of the more significant modeling results and developments are presented in the Peer Review report. Modeling work by groups or individuals outside LANL have not been discussed in either of our two reports.

\subsection{General Comments on Data Storage, Retrieval and Utility}

The data from the Fenton Hill project are stored in several ways, and their accessibility varies with the mode of storage. Much of the Phase I data, with the exception of seismic data and possibly the data from the last flow test (Experiment 217), are found only on paper, stored in file folders, in notebooks, and in the figures and tables of reports and memoranda on a given experiment or series of experiments. The seismic data from Phase I are stored on analog tapes, although maps of hypocentral locations have been presented in certain documents. The data from the last flow test of the Phase I reservoir (Experiment 217) are thought to be stored on computer diskettes, but we could not locate the digital data at LANL. Only computer printouts were seen. 
Much of the Phase II data of interest are stored in digital form, with the main exception being electrical logs, which are stored as paper printouts. Digital storage is common for most of the temperature logs and some of the gamma ray logs. As will be discussed below, the digital data is stored in various ways, and various levels of effort will be required for further evaluation or archiving.

The following is basic information on how data are stored at LANL.

- Two sets of experiment files are located in Jody Benson's office in the EES-4 building. One set (in the last filing cabinet against the wall with the window) is quite well organized and contains, for most experiments (Phase I: Experiments 105 - 217; Phase II: Experiments 2003 - 2074), write-ups of both the original proposal and the results, and in some cases, graphs or tables of results. The second, poorly organized set (in the second and third filing cabinets) has computer printouts and diskettes from some of the Phase II experiments.

- A well-organized collection of internal technical memoranda from 1978 through 1992 is stored in Mort Smith's office in the EES-4 building. Some of these memoranda were reviewed to get an idea of what kind of information is included. Most contain ideas for doing experiments (sometimes in the form of an experiment proposal) and/or write-ups of data analysis; however, little or no raw data were found in our brief review. LANL is in the process of optically scanning these documents in chronological order and storing them on CD-ROM. As of November 1998, scanning was complete through mid-1981, and was continuing.

- Hard copies (printouts) of many of the Phase II hydraulic fracturing data, early Phase II flow tests and part of the last Phase I flow test (Experiment 217) are located in the two right-hand file drawers beneath the mail sorting area in the EES-4 building.

- These same data sets and more are available on 5-1/4-inch diskettes from Zora Dash, whose office is also located in the EES-4 building.

- The office of Bob Potter, who was involved in many aspects of the Fenton Hill project, contains file folders and notebooks of data from many of the Fenton Hill experiments, from the earliest tests of GT-1 right through the Long Term Flow Test of the Phase II reservoir. It will require a great deal of effort to sort through this information; Bob has indicated that he will try to identify files and folders relating to the experiments listed in table 1.1. Due to limitations in the time and budget for this work, a systematic investigation of the information in this office was not attempted.

- Seismic event location data for some of the Phase II experiments are stored on the seismic group’s Unix system, and can be accessed by Leigh House, Mike Fehler and Scott Philips. Their offices are located in the building behind the EES-4 office. Zora Dash also has some of these data on 5-1/4-inch diskettes. 
- Raw seismic data from Phase I and Phase II are located on magnetic tapes in the seismic lab (Room S-10, in the basement of the Physics Building). Most are stored as analog signals; those from Experiments 2063 on are stored as digital signals. The tapes we saw were stored in boxes, labeled with the Experiment number on the outside and an index sheet inside showing which data were recorded on which channel. An Ampex FR-2000A tape drive, which could presumably be used to read the analog tapes, is located in the seismic lab; its condition is unknown.

- Also in Room S-10 were banker's boxes containing files put in storage by Don Brown and perhaps other people involved in the project. We made no attempt to determine their contents, but LANL personnel suggested that some of the Phase I and perhaps even some of the Phase II data might be stored in them.

- A complete set of daily drilling records, daily operational logs of drilling and fracturing operations made by LANL personnel and paper copies of most of the well logs run by outside contractors (temperature, cement bond, resistivity, caliper, gamma, etc.) from both the Phase I and Phase II wells are stored in an office at the Fenton Hill site itself.

- Many Phase II temperature logs and a few gamma and caliper logs are stored on the Unix system. Zora Dash can provide access to these. Older temperature logs are probably stored only as printouts (tables and/or plots) in the experiment files, reports, memoranda, and possibly in Bob Potter's office.

- Data from the later Phase II flow tests (after Experiment 2077; see table 1.1) were collected by the DMACS data acquisition system, which uses a proprietary code to store data on a PC. Pressure, temperature and flow rate data were stored in this system at 10second intervals; other data were stored at longer intervals (up to 10 minutes in some cases). Bob duTeaux, a graduate student in Petroleum Engineering at Stanford University, has written a program to extract some of these data from the DMACS system. Further work is required to extract all of the information.

- Bob duTeaux has other data of interest from this same period, including tracer test results and most if not all of the temperature and pressure logs.

- Finally, it should be noted that some data are included in various forms (tables, plots, maps, etc.) in the numerous (about 800) reports and papers that have been published on the Fenton Hill project. Correlating the data sets of interest with the published literature is part of the Fenton Hill Data Indexing and Archiving task; PERI is coordinating the effort on this.

It is clear that, in a general sense, preservation of the data from Fenton Hill has not been a priority to date. Some of the information has already been lost, and more is clearly at risk of being lost, either because it will be thrown out (primarily to make space), or because it cannot be recovered from storage. Examples of the latter include information recorded on magnetic media (tapes and floppy disks which have deteriorated and/or cannot be read because the hardware is unavailable) and information included in the (paper) files of various individuals, which have 
been stored in various places. There is no active HDR program at LANL at present, and there is reportedly no funding available to assist in data recovery or archiving. One exception to this is the optical scanning of the internal memoranda discussed above.

Certain individuals have retained information that is of interest to them. For example, some of the seismic data have been preserved and are accessible because there is continuing interest in their evaluation. However, retrieving the complete set of data from Fenton Hill (or even the subset identified in table 1.1) would be a huge undertaking, and would necessarily involve LANL personnel. There are two reasons for this: they know where the data are stored; and there are certain aspects of the data collection that play a role in its evaluation and that are known only to the people who were involved in acquiring the data.

For example, information on station corrections for the pre-Cambrian seismic network or on glitches in data recording, which certainly are necessary to evaluate the seismic data, may only be recorded in the field notebooks of the people involved in collecting the seismic data from a particular experiment (Jim Albright, Mike Fehler, Leigh House and others). Another good example of this relates to well operations during hydraulic fracturing, particularly during Phase I. The details of well completion, pumping rates and pressures, all pertinent to an evaluation of what it takes to break down the formation, can in some cases only be known by reviewing files or field notes of certain individuals. Therefore, the cooperation and assistance of LANL people would be needed to collect, identify and interpret much of the data of interest.

Table 1.1 was developed with the idea that creating the reservoir (by hydraulic fracturing), mapping the reservoir (by collecting and analyzing seismic data) and evaluating the reservoir (by flow testing, tracer testing and well logging) are the information from the Fenton Hill HDR project that would be most useful to future developers of EGS. We did not anticipate being able to find all of the information that relates to the operations listed therein; however, table 1.1 provided a useful framework for discussion with present and former LANL personnel regarding the data from the project. In GeothermEx's opinion, these data are the most useful for transferring the experience gained at Fenton Hill to other EGS projects. This transfer of information can serve to promote the development of the vast geothermal resource base in the U.S. that is accessible but limited in terms of permeability and/or fluid content.

\subsection{Acknowledgments}

As in the case of the Peer Review, everyone interviewed at LANL regarding the data from the Fenton Hill project was extremely cooperative and informative, both during the interviews and during follow-up phone calls and requests. GeothermEx gratefully acknowledges the helpful attitude of present and former LANL staff members towards this work. 


\section{HYDRAULIC FRACTURING AND WELL PRESSURIZATION DATA}

\subsection{Introduction}

The HDR reservoir at Fenton Hill was created by fracturing the reservoir rock. Water was pumped into the wells at high pressure, into selected intervals that were isolated from the rest of the well using one of several methods. The way in which the well was completed is therefore important to understanding a given hydraulic fracturing operation.

It is thought that during Phase I a single major fracture and was created, and numerous preexisting weaknesses in the rock (probably joints) were opened, thus enlarging the system. In Phase II, no major fracture was created, and the reservoir consisted entirely of a network of joints that opened at various pressures. It was recognized that the volume of the network was proportional to the volume of water injected, and progressively larger volumes of water were injected during hydraulic fracturing operations as the project proceeded.

\subsection{Data of Interest}

The data of interest from hydraulic fracturing include:

- the lithology and petrology of the zone selected for fracturing

- pertinent well completion and status information that explains the depth and method of isolating the zone to be fractured

- injection rate, pressure and temperature as functions of time

- $\quad$ transient pressure data collected after shut-in

- $\quad$ venting rate, pressure and temperature as functions of time

- the locations of pressure measurements (wellhead or downhole), to enable appropriate corrections to be made as needed

- information on the types and amounts of friction-reducing chemicals used in the operations, if any

In addition, there were several tests made of individual wells or a reservoir system (a pair of wells and the reservoir in between them) that involve aspects of well pressurization, well testing and reservoir analysis. During these, pressure was applied at one point and various observations were made at others, but no flow from the system was permitted. Because these experiments involved pressurizing the wells, we include them in this chapter for completeness. However, the well pressurization data are required only as background information to use in the analysis of seismic data (in the case of acoustic ranging or shear-shadowing experiments; see Chapter 3) or determination of reservoir hydraulic properties using methods similar to those used to analyze 
well test data (in the case of long-term reservoir pressurization and leak-off tests; see Chapter 4).

\subsection{Experiments of Interest and Location of Data}

\subsubsection{Phase I}

We were unable to determine Experiment numbers for the earliest work done at Fenton Hill; however, hydraulic fracturing information of interest was generated during these early days, and we have therefore included this work in table 1.1. As mentioned in Chapter 1, we found experiment files beginning with Experiment 105 (undertaken in December 1975), but the earliest experiment of interest that we were able to identify with a number was 117 . We could not correlate any of the experiment files from 105 to 116 with any of the experiments of interest listed prior to Experiment 117 in table 1.1.

The earliest data (table 1.1, items 1 through 4) are from wells GT-1 and GT-2 (original hole or $(\mathrm{OH})$, conducted when the well had reached a total depth or (TD) of 6,700 feet). Most of the data of interest can be found in the daily operational logs kept at Fenton Hill, and some can be found in a LANL report by R.L. Aamodt ("Hydraulic fracture experiments in GT-1 and GT-2," Report number LA-6712). Possible alternate sources include: 1) the files in Bob Potter's office; 2) Don Brown's files in storage in Room S-10; and 3) internal memoranda, although we found few memoranda from this time period (1973 - 1974).

GT-2 was later deepened to 9,619 feet and two more stimulations were performed (table 1.1, items 5, 6 and 13), and well EE-1 was fractured at least twice at a TD of 6,886 feet in August 1975 (item 7). The daily operational logs at Fenton Hill would be the best source of information, and the three alternate sources mentioned above also are possibilities.

During the drilling of EE-1, when the well had reached various depths (6,886 feet; 9,100 feet; 9,575 feet; and 9,877 feet), LANL undertook a series of experiments to investigate the connection between EE-1 and the original hole of GT-2 (table 1.1, items 8 - 12 and 14 - 16). This included running spontaneous potential logs in one well and induced potential logs in the other (SP/IP logging, while maintaining the wells at various pressures), and acoustic ranging, to determine the distance between the two wells by detonating charges in one well while recording seismic signals in the other. The well pressurization data would be required to evaluate the utility of the method and the results of the experiment, and this information should be included in the daily operational logs stored at Fenton Hill; it may also be included in the three possible sources mentioned above.

At its final TD of 10,053 feet, well EE-1 was hydraulically fractured again (item 17). Data of interest would be found in the same sources previously mentioned.

Beginning in March 1976, LANL then conducted another series of experiments to investigate the EE-1 / GT-2 system (Experiments 117, 122, 126, 127, 129, 145, 146, 150, 159, and 160), including acoustic ranging (sometimes using a mechanical device to generate the signal), shearshadowing (a technique similar to acoustic ranging, designed to determine the presence and in 
some cases the geometry of fluid-filled fractures between the seismic source and the receiver) and IP logging. The pressure conditions of the wells during these experiments would be included in the daily logs and are also usually presented and discussed in the write-ups of the results of the experiments (see the experiment files in Jody Benson's office).

Well GT-2 was then redrilled twice; the final hole is referred to as GT-2B. At a TD of 8,767 feet, GT-2B was hydraulically fractured in June 1977 (Experiment 166). An operations history is included in the daily logs kept at Fenton Hill, and information is also included in the experiment file.

The EE-1 / GT-2B system was then investigated. No experiment file could be found for Experiment 172, which included step-pressurization (injection) tests of each of the two wells with the other shut in. Two shear-shadowing experiments (174 and 185) were conducted, and well pressurization data from the first of these are in the experiment file. There was no write-up of results in the Experiment 185 file. The operational logs on site should be reviewed for further information.

EE-1 was then hydraulically fractured (Experiments 203 and 195). Most of the data of interest are included in the write-ups in the experiment files, and more data can be found in the operational logs on site.

For all of the Phase I hydraulic fracturing experiments, lithologic and petrologic information about the fractured interval can be determined generally from Laughlin et al., 1982 ("Geology of the Fenton Hill, New Mexico, Hot Dry Rock Site,” Journal of Volcanology and Geothermal Research, Volume 15, pp. 21 - 41) and more specifically from the LANL reports cited therein. The Phase I reservoir was developed in what is broadly described as a biotite granodiorite unit, although Laughlin et al. noted other lithologies in the numerous cores collected from GT-2 and in the two cores that were collected from EE-1.

\subsubsection{Phase II}

Experiments in the Phase II reservoir began in January 1982 after wells EE-2 and EE-3 were completed. By this time, a data acquisition system was in place that used a Hewlett Packard (HP) 9845 computer system, with data stored on 8-inch diskettes. The original 8-inch diskettes are stored in a metal file cabinet in the EES-4 computer room. Most of these data were later converted for use by the HP 9816 / 9836 system, which uses 5-1/4-inch diskettes; these are stored in Zora Dash's office. One of the two HP computers is in Zora's office, and the other is in the EES-4 computer room. Both were functioning the last time they were used. Unless otherwise noted, data can be found in four places: 1 ) on the original 8-inch diskettes for the HP 9845 system; 2) on 5-1/4-inch diskettes for the HP 9816 / 9836 system; 3) in the experiment files in Jody Benson's office; and 4) as hard copies (printouts) in the right-hand file cabinets beneath the EES-4 mail sorting area.

The data stored during hydraulic fracturing or other well pressurization experiments typically included: the wellhead temperature and pressure of the well being fractured; the flow rate into the well being fractured; flow rates measured at the pump trucks; the annulus (i.e., backside) 
pressure and flow rate in the well being fractured; and, in some experiments, the pressure, temperature and flow rate information from an observation well (EE-3 when EE-2 was being fractured, and vice versa).

The operational logs at the Fenton Hill site also contain basic operational information, including the amount and type of chemicals used to reduce friction during hydraulic fracturing.

With respect to hydraulic fracturing and well pressurization, the following Phase II experiments are of interest (also see table 1.1):

- open-hole injection tests in both wells: Experiments 2003, 2006, 2007 and 2023 (no hard copies by the mail sorting area except 2023)

- initial hydraulic fracturing of EE-2: Experiments 2011, 2012, 2016, 2018, 2019 and 2020 (no experiment files for 2019 and 2020; no hard copies near the mail sorting area for 2011 or 2020)

- hydraulic fracturing of EE-3: Experiments 2025 and 2033 (no printout of 2033 by the mail sorting area)

- the massive hydraulic fracture (MHF) of EE-2: Experiment 2032 (Zora Dash also has files from this experiment on the Unix system)

- the MHF of EE-3: Experiment 2042

- additional fracturing of EE-2 after its first repair job: Experiment 2052

- after redrilling EE-3 as EE-3A during the first half of 1985, fracturing in EE-3A during the second half of 1985 and early 1986: Experiments 2059, 2061, 2062 and 2066

Geologic data from the original holes of EE-2 and EE-3 can also be found in the Laughlin et al. report mentioned above. In addition, Schoen Levy of LANL prepared a detailed report on the geology of the cores and cuttings from EE-2A and EE-3A, that included an analysis of the upper parts of those wells (i.e., the original holes down to the kick-off points). Unfortunately, because funding ran out before it was completed, this report was never published. As it contains detailed petrologic information, including analyses of the natural, closed fractures in the reservoir which are thought to have opened during pressurization, it may be germane to the evaluation of hydraulic fracturing results at Fenton Hill.

Tests of the Phase II system which involved pressuring up the wells and evaluating the response of the reservoir include:

- Experiment 2070 (injection into EE-3A)

- Experiment 2076 (injection into EE-2A) 
- Experiment 2077 (a long-term leak-off test to evaluate reservoir volume and storage at various pressures)

- the long-term pressure maintenance of the reservoir from May 1993 to May 1995 (between the Long Term Flow Tests and the Reservoir Verification Flow Tests)

Data from Experiment 2070 are found in all four places mentioned at the beginning of this section. The only source of data we found from Experiment 2076 is the printout located near the EES-4 mail sorting area. Zora Dash has the data from Experiment 2077 on the Unix system. The 1993-1995 long-term pressure maintenance data are stored in the DMACS system mentioned in the introduction of this report.

\subsection{Further Analysis of Data}

Well stimulation by hydraulic fracturing was the means used to create the Fenton Hill HDR system. It is taken for granted that future EGS experimentation in low permeability reservoirs will involve well stimulation, and that hydraulic fracturing will be the primary technique used. Therefore, preservation of the Fenton Hill experience with hydraulic fracturing would be a logical step in transferring the findings of this project to interested stakeholders. This information could be best be presented as tables and/or plots of various parameters versus time, appropriately annotated with information similar to that presented in table 1.1 (well, date, experiment number, description of operation), plus information on the well completion, zone isolation and lithology/petrology data. To the best of our knowledge, there is no single source of such information which presents the Fenton Hill experience with hydraulic fracturing.

These data might be further evaluated to determine how the state of stress changed during sequential fracturing jobs, to determine the change in orientation of fractures with depth and location (in combination with well log and seismic data), or to determine how the reservoir grew as operations proceeded. Like most other suggestions for further data evaluation discussed in this report, an integrated analysis of other types of data (seismic, well log, etc.) would be required to learn anything further from the hydraulic fracturing information. 


\section{SEISMIC DATA}

\subsection{Introduction}

During the process of creating and testing the reservoir at Fenton Hill, microseismic events were produced, the seismic activity was monitored, and data were collected. In some experiments, calibration shots were used to make corrections at each geophone station, which were then applied when the signals from that station were analyzed.

Raw seismic data consist of waveforms recorded by geophones (or in some experiments, by accelerometers) deployed either at the surface or downhole in conveniently located wells. During Phase I and part of Phase II, these waveforms were recorded as analog signals on magnetic tape. In the later part of Phase II (Experiment 2063 on), a seismic data collection system (the MASSCOMP system) was used to store the waveforms as digital signals on magnetic tape. These waveforms were analyzed in various ways by LANL personnel and others.

Of primary interest was the determination of the locations (hypocenters) of the seismic sources. A map of these locations is essentially a map of reservoir fractures, which is where heat transfer may occur under production conditions. To determine these locations, two methods were used: hodograms and triangulation. The hodogram technique utilizes a graphical representation of the movement of the earth in the $\mathrm{x}, \mathrm{y}$ and $\mathrm{z}$ directions at a single geophone array of known orientation to determine the direction to a seismic source. A seismic velocity model is used to determine the distance to the source from the difference in arrival times of the P- and S-waves. The locations determined with hodograms tended to define arc-shaped structures that result from the uncertainty in the direction to the source; that is, it is an artifact of the method of location rather than representing a real structure in the reservoir.

Triangulation uses the data from three or more geophone arrays to determine the hypocentral location, and is thought to be more reliable. Interestingly, the locations determined by triangulation were often parallel to the wellbore rather than intersecting it as had been observed from the hodogram locations.

Even with triangulation techniques, there is a certain margin of error in the location of events. Methods have been used (such as doublet or cluster analysis) to correct the locations of events relative to other events; other statistical techniques (such as the three-point method or data collapsing) have been applied to determine if there is a genetic relationship between events or groups of events (e.g., if they occur along a common plane).

\subsection{Data of Interest}

The raw seismic data of interest include:

- basic station location information, including depth and coordinates if the geophones were deployed downhole

- the type of tool used (geophone or accelerometer) 
- basic information from calibration shots (source location, depth, charge size and signals recorded at all stations)

- the actual waveforms collected during an experiment

Interpreted data of interest include:

- the seismic velocity structure of the volume of rock under investigations

- station corrections from calibrations shots

- hypocentral locations and the estimated range of error

- planes or other features identified from statistical analysis of the data

- analyses of earthquake source mechanisms

- analyses of long-period events, which have been identified in some of the data from Fenton Hill

\subsection{Experiments of Interest and Location of Data}

\subsubsection{Phase I}

The main experiments of interest are those involving hydraulic fracturing of the wells, which are the same data sets discussed in the previous chapter. Of secondary interest are the acoustic ranging and shear-shadowing experiments also discussed therein. In addition, there were a few flow tests during which microseismicity was observed and seismic data were collected. These include Experiments 215 (Run Segment 4) and 217 (Run Segment 5, particularly the Stress Unlocking Experiment at the end of this test).

Raw data are stored in various places. Station locations, geophone depths and tool types are usually included in the experiment files in Jody Benson's office; information on calibration shots is in the experiment files or in the field notebooks of Jim Albright, Mike Fehler, Leigh House or others; and waveform data are stored as analog signals on magnetic tape in the seismic lab (room S-10 in the basement of the Physics Building).

As in the case of the hydraulic fracturing data, the seismic data from the earliest experiments are likely to be very difficult to compile. Although we did not make an inventory of the experiments indicated on the labels of the tape boxes in the seismic lab, we took note of the lowest and highest experiment numbers that could be easily seen without having to move many boxes. The lowest Phase I number we saw was Experiment 109. Although the highest we saw was 176, it is likely that the rest of the Phase I seismic data are there too. 
Interpreted data from Phase I are sometimes found in the experiment files, and more commonly in published reports. Maps of hypocentral locations are by far the most common interpreted data to be found. Printouts of hypocentral locations for a few experiments were also seen in Bob Potter's office.

\subsubsection{Phase II}

Raw data from Phase II are located as indicated above for the Phase I data. No experiment file could be found for Experiment 2052 (the last fracturing job in EE-2 before it was redrilled). From Experiment 2063 on, the MASSCOMP system was in place and the waveforms were stored as digital signals (rather than analog signals) on magnetic tape. The waveforms from Experiment 2032 were digitized into the MASSCOMP system for later analysis and can therefore probably be found on both analog and digital tape.

Certain individuals have retained digital files of event locations. Zora Dash has this information for Experiments 2032, 2042, 2052, 2061 and 2062 on 5-1/4-inch diskettes for the HP 9816 / 9836 system. Leigh House has the same data on the Unix system in his home directory, plus locations from Experiments 2063, 2066 and 2067. The last is the Initial Closed-Loop Flow Test of the EE-2/EE-3A system, which was nearly aseismic. Mike Fehler has locations from Experiments 2032, 2061, 2062 and 2066 (also on the Unix system), plus a limited set of waveform data from Experiment 2032 (these data sets are very large and thus require a great deal of disk space to store). Scott Philips may also have this same limited set of waveform data stored on the Unix system.

Reports have been published that include maps of hypocentral locations and the results of other analyses, including clustering analysis, the statistical determination of common planes of activity, and the nature of the long-period events detected during Experiment 2032.

No downhole seismic data were collected from the later Phase II flow tests (in the 1992 - 1995 time period); only surface stations were available, and the data from these is considered to be of limited use for resource evaluation owing to attenuation effects.

\subsection{Further Analysis of Data}

Opinions are mixed about the value of further analysis of Phase I seismic data. Some feel that because of the problems with the hodogram method for locating events, it would be unwarranted to spend any time trying to recover and re-interpret these data. Others feel that application of newer techniques that were just being developed at the time the Fenton Hill data were collected could be applied successfully and more could be learned about the structure and character of the Phase I reservoir. In particular, the data from Experiments 203, 195 and 204 (hydraulic fracturing and flow testing of EE-1; see table 1.1) and the Stress Unlocking Experiment at the end of Run Segment 5 (Experiment 217) are thought to be good enough to merit re-evaluation using some of the newer techniques described in the following paragraph. 
A small amount of analysis of Phase II waveform data collected from the stations in the preCambrian net for information other than arrival times has been done, but more remains to be done in the areas of waveform scattering techniques, clustering analysis to reduce relative location errors, statistical analysis to identify structures, and frequency analysis. Additional analysis of seismic data may reveal information about microseismic source mechanisms, phase distribution in the reservoir (probably not relevant at Fenton Hill), fracture geometry, the location(s) of productive areas of the reservoir, and changes in the reservoir with production and injection over time.

Of particular interest is an evaluation of long-period events, which were identified after extensive filtering of the data from Experiment 2032. One explanation of these events is that they result from the tensile opening of joints or fractures (as opposed to the more easily identifiable shear movement), but other mechanisms have been proposed, such as resonance (induced by microseismicity) in fluid-filled fractures. A systematic evaluation of these events could yield some insight into both their source mechanism(s) and their utility for reservoir analysis.

The hypocentral location data from several sequential fracturing jobs conducted in EE-2 and EE-3A could be reviewed with a view toward analyzing the growth of the reservoir. In EE-2, experiments 2018 and 2020 were conducted before the MHF (Experiment 2032). Experiments 2059, 2061, 2062 and 2066 represent similar series of fracturing jobs conducted in EE-3A. The breakdown behavior of the rock and the growth of the reservoir could be more fully evaluated using a combination of hydraulic fracturing seen on formation well log analysis and the seismic data. Unfortunately these fracturing jobs did not establish pressure communication between the two wells, so no flow or tracer tests could be conducted between the jobs to give an independent quantitative confirmation of reservoir growth.

Any further evaluation of the Phase II data will have to consider certain problems associated with the data collection and interpretation. The so-called pre-Cambrian net, in place from Experiment 2032 on, consisted of downhole stations in wells EE-1, EE-2 or EE-3 (depending on which well was being fractured), GT-2, and two wells drilled specifically for the net (PC-1 and PC-2). Well PC-1 was completed in a granite rubble zone that was presumed to lie on top of the pre-Cambrian basement, and PC-2 was completed in the limestone unit that overlies the basement (and presumably also the granite rubble zone mentioned above, but the continuity of this zone not certain). Because these last two wells did not actually penetrate into the basement, large station corrections were needed to account for delays and attenuation. The slim (3-1/2-inch diameter) tool typically used in well EE-3 had certain problems (the P-arrivals were relatively small compared to the S-arrivals), and the accelerometers sometimes deployed in well GT-2 gave unreliable data because they did not function well for extended periods at high (i.e., downhole) temperatures. Reliable signals were always recorded by the 6-inch diameter geophone package deployed in well EE-1.

The calibration shots, used to determine station corrections, were made by detonating up to 30 feet of primacord. Because a point source of energy is preferred, this may introduce some error in the station corrections. 
As mentioned in the introduction, LANL personnel would needed to make sense of the data before any further evaluation is made, and appropriate hardware and software would have to be obtained to enable the tapes to be read and translated to another digital medium. The Ampex tape drive in the seismic lab may be functioning, but this could not be verified. If the needed information relating to data collection can be obtained, further evaluation of the Fenton Hill microseismic data would yield important information about the nature of artificially and naturally fractured reservoirs.

The Japanese government has sponsored two projects specifically relating to the evaluation of seismic data from EGS: More Than Cloud (MTC) and Post-More Than Cloud (post-MTC). The project names refer to the seismic cloud, a phrase often used to describe the seismically active zone during hydraulic fracturing or testing operations. Several LANL Fenton Hill Project staff (including seismologist Mike Fehler) and a group of international collaborators are participants in these projects, which are led by Dr. Hiroaki Niitsuma of Tohoku University. Further evaluation of the seismic data from Fenton Hill may occur under the auspices of these projects, and others undertaken by various individuals and organizations in Europe. These should be reviewed fully before any additional evaluation is contemplated to avoid duplication of effort. 


\section{FLOW TEST DATA}

\subsection{Introduction}

Three types of flow tests were undertaken at Fenton Hill: 1) brief injection tests or other tests to evaluate the results of a certain operation undertaken in a well; 2) longer-term tests designed to evaluate the response of the reservoir to production conditions; and 3) monitoring of the reservoir during periods of pressure maintenance and venting (discussed briefly in Chapter 2).

Tests of the first type, usually several hours long, were undertaken to evaluate the injectivity in a well, or to obtain impedance or reservoir volume information at various pressures. Such tests were typically carried out before or after a hydraulic fracturing operation, or after a well had been redrilled to intersect an area of created permeability. One or two wells may have been involved.

The second type of tests always involved two wells (injection and production). During Phase I, well EE-1 was used for injection, and well GT-2 (or later, GT-2B) was used for production. In the test of the Phase II reservoir, well EE-3 (or EE-3A) was used for injection and EE-2 (or EE2A) was used for production. These tests revealed information about the long-term production characteristics of the system, and the data from them were often matched using heat-transfer and other numerical models.

The last type of tests were conducted late in Phase II and may have been the by-product of a desire to keep the system inflated (i.e., pressurized) during long periods during which there was little activity on the Fenton Hill project. One such test occurred from late 1988 to late 1991 (after EE-2 was redrilled as EE-2A, and before the first phase of the Long Term Flow Test); another occurred from May 1993 to May 1995 (after the second phase of the Long Term Flow Test, and before the Reservoir Verification Flow Tests).

\subsection{Data of Interest}

The data of interest from flow tests include:

- diagrams and other appropriate information that describes the types and locations of measurement points

- injection and production rates as functions of time

- $\quad$ wellhead pressure and temperature as functions of time

- downhole pressure as a function of time (if data were collected)

- rates, pressures and temperatures of annular leakage as functions of time

- pressures or water levels in observations wells as a function of time (wellhead data were collected in GT-2 and EE-1 during some of the Phase II flow tests) 
- rates, pressures and temperatures of venting after shut-in as functions of time

- transient data (pressures or water levels as functions of time) collected upon shut-in

\subsection{Experiments of Interest and Location of Data}

\subsubsection{Phase I}

The first injection test of EE-1 was undertaken in March 1976 (Experiment 117); no production was permitted from well GT-2. Shortly thereafter, a two-day flow and tracer test was conducted (Experiment 115). In November 1976, a 10 day-flow and tracer test of the Phase I First Reservoir (Experiment 137) was carried out prior to a silica leaching experiment. A limited amount of data exist from these tests is included in the experiment files in Jody Benson's office, and possibly in the files in Bob Potter's office or in the boxes in storage in the seismic lab.

After GT-2 was redrilled as GT-2B and hydraulically fractured, a series of tests were conducted in 1977 to evaluate the EE-1 / GT-2B system (still referred to as the First Reservoir). This began with Experiments 170 (a 12-hour flow test) and 172 (step-pressurization of each of the two wells in turn). No experiment file was found for Experiment 172; therefore, the only likely sources of data would be Bob Potter's office or the boxes in the seismic lab.

Thereafter began a series of longer tests to evaluate the EE-1 / GT-2B system referred to as Run Segments 1, 2 and 3. Run Segment 1 was a four-day preliminary test conducted in September 1977 to verify that the surface equipment was operating properly, and Run Segment 2 was a 75day test of the system conducted in early 1978. These two tests are collectively referred to as Experiment 176. Run Segment 3 (Experiment 186) was a 30-day test conducted in September and October 1978. A test of the system impedance at low backpressure (Experiment 190) was then conducted. The primary sources of data for these tests would be the experiment files and the files in Bob Potter's office; however, no experiment file was found for Experiment 190.

EE-1 was then fractured again in March 1979 (Experiments 203 and 195), creating what is referred to as the Second Reservoir, and a flow test (Experiment 204) was carried out just after this fracturing job. Data are in the experiment files, in a 27 March 1979 office memorandum from J.W. Tester and others to Rod Spence, and possibly in Bob Potter's office.

The EE-1 / GT-2B system was tested again in October and November 1979 (Experiment 214 or Run Segment 4). No data was found in the experiment file from this test; some may exist in Bob Potter's office.

The final test of the Phase I reservoir was Run Segment 5 (Experiment 217, which includes the Stress Unlocking Experiment), a 286-day test conducted in 1980. This was the first test for which we were able to find evidence of digital data storage. There was a printout of some of the data from this test in the file drawers in the mail-storage area, and there has been extensive reporting on this test (e.g., Dash et al., 1981, "Hot Dry Rock Reservoir Testing: 1978 to 1980," LANL report number LA-9080-SR). We believe that data were collected on the HP 9845 
computer system and should therefore be stored on 8-inch diskettes. However, none of the 8inch disks in the EES-4 computer room appeared to include these data. Further searching should yield the data of interest in digital form. Zora Dash would be the best person to assist such a search.

\subsubsection{Phase II}

The early Phase II flow tests evaluated EE-2, EE-3 and the EE-2 / EE-3A system. Unless otherwise noted, the data of interest from this period can be found as printouts in the file cabinets near the EES-4 mail sorting area, and on 5-1/4-inch diskettes for the HP 9816 / 9836 system in Zora Dash's office. In addition, some of the data from these tests are stored on the original 8inch diskettes for the HP 9845 system.

The following data of interest are stored in this manner:

- $\quad$ open hole injection tests in wells EE-2 and EE-3: Experiments 2003, 2006, 2007 and 2023 (no printouts except for 2023)

- the Initial Closed-Loop Flow Test (ICFT) of the EE-2 / EE-3A system: Experiment 2067 (Zora Dash has the complete data set and a reduced set with 15-minute averages stored on the Unix system)

- $\quad$ venting of EE-2 after the ICFT: Experiment 2068

- injection into EE-3A to evaluate post-ICFT pressures: Experiment 2070

EE-2 was then re-drilled as EE-2A, and another series of tests was conducted. The flow tests of interest are Experiments 2074 (a six-day flow test in December 1987), 2076 (a one-day injection test in EE-2A) and 2077 (a series of reservoir leak-off tests during which the reservoir was pressurized and vented several times). Only printouts (by the mail sorting area) could be found for the first two, but it is highly likely that digital data could be found by Zora Dash. For Experiment 2077, which spanned the period from late 1988 through December 1991, Zora has files of pressure data versus time on the Unix system, but no injection rate information. A box of 8-inch diskettes that includes some of the pressure monitoring data was also found. It was suggested that the injection rate data might be found on the DMACS system, but Bob duTeaux indicated that the first DMACS data were collected in December 1991.

Data from the later flow tests of the Phase II system, which do not have experiment numbers as far as we know, are stored in the DMACS system. As mentioned in the introduction, some of the data has been recovered from this system; more remains to be recovered. The tests of interest include:

- four preliminary flow tests of the Phase II system (December 1991 through March 1992)

- the first phase of the Long-Term Flow Test (April to July 1992) 
- an interim flow test (August to October 1992)

- two tests at high back-pressure (December 1992 to January 1993)

- the second phase of the Long-Term Flow Test (February to April 1993)

- the cyclic flow tests (May 1993)

- long-term pressure and temperature monitoring with pressures maintained by periodic injection (May 1993 to May 1995)

- the first phase of the Reservoir Verification Flow Test (May to June 1995)

- the second phase of the Reservoir Verification Flow Test (June 1995)

- a load-following experiment (July 1995)

- a final flow and tracer test (July 1995)

\subsection{Further Analysis of Data}

Further evaluations of the Fenton Hill flow test data could be undertaken to better understand the size of the reservoir, its hydraulic properties and heat-transfer characteristics under various operating conditions. Subsequently, energy production from the reservoir could be optimized by numerical simulation. The results of such analyses would have obvious implications for other developers of EGS.

A relatively thorough analysis has been made of the flow test data from Phase I in terms of reservoir temperature behavior and system impedance. However, it would be useful to have some additional analysis of Phase I data to confirm the conclusion that the reservoir was growing during the test. This is a very important result that should be investigated by an integrated analysis of all of the reservoir data, including evaluation of transient pressure data, which have not been fully evaluated. This integrated analysis could then be used to develop a numerical model of the Phase I system, which, in turn, could be used to optimize heat recovery.

LANL staff have indicated that there was very little budget available to do any in-depth analysis of the Phase II test data; interested parties outside LANL continue to evaluate this information. Some of this evaluation is being undertaken to validate numerical models of HDR systems, but there is more to be gained from looking more fully at the Phase II flow test data. A great deal of pressure transient data were collected, particularly from the later Phase II tests, which were often interrupted for operational reasons (pump failures, etc.). These need to be more fully evaluated. The long-term leak-off test and pressure monitoring data have been used by LANL to estimate the opening pressures of various joint sets in the reservoir, but these data could also be used to infer how reservoir storage and other hydraulic properties of the reservoir vary with pressure. To 
undertake an evaluation of this type, further work will be needed to extract the data from the DMACS system.

With appropriate input data from other disciplines that define the reservoir, the additional production from two or more production wells (instead of one) could be estimated (LANL has done some preliminary work on this). In a similar vein, a coupled wellbore-reservoir model could be developed to evaluate energy production and well behavior at various operating pressures. For these types of studies, well test data would be used to calibrate a model of the reservoir, thus enabling predictions of future performance to be made under various operating scenarios.

It has been inferred that a connection was made between the Phase I and Phase II reservoirs at Fenton Hill, either through the reservoir or via the annulus of the injection well. A further evaluation of observation well data and other data (seismic, tracer and well log) may confirm the connection, and the mechanism of connection could be evaluated.

Another program sponsored by the Japanese government which evaluates flow test and other data from EGS reservoirs is the Multi-Disciplinary Understanding of Reservoir Physics (MURPHY) program. Several individuals from LANL are involved in this project, and it is possible that additional evaluation of Fenton Hill flow test data is being or will be undertaken under the auspices of the MURPHY program. Again, this should be reviewed before any new analyses are undertaken. 


\section{TRACER DATA}

\subsection{Introduction}

Tracer tests were carried out during both Phases of the Fenton Hill project. Techniques were developed at LANL to analyze the data collected, and the estimation of reservoir volume at a given pressure was the main end product. Modal volume (or volume of fluid produced between the time the tracer was injected and the time of peak return concentration) was used to represent the fastest path through the reservoir, and integrated mean volume (or volume of fluid produced between the time the tracer was injected and the time the tracer return concentration becomes negligible) was used to represent the total volume of the system. By analyzing these volumes, the shapes of the tracer return curves, and temperature data, inferences are also made regarding heat-transfer efficiency, short-circuiting and the general nature of the reservoir.

The tracer data were often used as a basis for developing heat-transfer or numerical models of the Fenton Hill system. For example, the large modal volume (80\% of the integrated mean volume) in the Phase I reservoir indicated that permeability was dominated by a major fracture; this information was then used in developing the independent fractures and multiple fractures heat-transfer models. In the Phase II reservoir, the modal volume was about $30 \%$ of the integrated mean volume, implying a distributed network of fractures. This information was then used as input to a numerical model (FRACNET), which considers isothermal fluid flow through a pressure-dependent set of fractures with permeability being proportional to fracture aperture.

Although such models are non-unique, the tracer data provide a good basis for testing a given reservoir concept, and were used effectively for that purpose at Fenton Hill. It is likely that tracer techniques will be used extensively in developing future EGS reservoirs.

\subsection{Data of Interest}

The data of interest related to tracer testing include:

- the date and time of tracer injection

- the location of the tracer injection point (i.e., the well in which the tracer was injected)

- the type, amount and concentration of tracer injected

- observed tracer concentrations at the observation well(s) as functions of time

- downhole gamma ray logs, if run to detect a radioactive tracer

- $\quad$ pertinent flow test data on which any analysis of tracer results must necessarily be based (see data described in the previous chapter) 


\subsection{Experiments of Interest and Location of Data}

\subsubsection{Phase I}

The first tracer tests at Fenton Hill used sodium fluorescein (Na-F, a widely used tracer which can be analyzed using relatively simple fluorometric equipment and techniques), which was injected into well EE-1 and sampled at GT-2(OH) to evaluate the Phase I First Reservoir. The first tracer test was conducted in March 1976 (Experiment 115), and a second (Experiment 137) was conducted in November 1976, prior to a silica-leaching experiment undertaken to try to reduce reservoir impedance.

After redrilling of well GT-2 as GT-2B, several additional tracer tests were undertaken in the Phase I Second Reservoir, with EE-1 as the injection well and GT-2B as the production well. During Run Segments 2 and 3 (Experiments 176 and 186, respectively), a total of seven Na-F tests were conducted.

EE-1 was then hydraulically fractured, creating the Second Reservoir, and four more Na-F tests were conducted during Run Segment 4 (Experiment 215). During Run Segment 5 (Experiment 217, including the Stress Unlocking Experiment), one Na-F tracer test was run, and five tracer tests used an irradiated ammonium bromide solution $\left(\mathrm{NH}_{4}{ }^{82} \mathrm{Br}\right.$ ). Samples for the $\mathrm{NH}_{4}{ }^{82} \mathrm{Br}$ tests were analyzed using a flow-through gamma counter fabricated by LANL.

Tracer return curves are presented in several LANL reports; LA-9080-SR ("Hot Dry Rock Geothermal Reservoir Testing: 1978 to 1980") is a good source of this information. Raw data may be stored in Bob Potter's office. The experiment files also include a limited amount of tracer data.

\subsubsection{Phase II}

The first tracer tests of the Phase II reservoir were apparently conducted in connection with hydraulic fracturing in well EE-2 (Experiment 2052, April - May 1985); both Na-F and irradiated bromide tests are reported. During the Initial Closed-Loop Flow Test of the EE-2/EE3A system (Experiment 2067, May - June 1985), two tracer tests were conducted using an irradiated iodide $\left({ }^{123} \mathrm{I}\right)$ solution.

After redrilling EE-2 as EE-2A, a six-day flow test was conducted with injection into EE-3A and production from EE-2A (Experiment 2074, December 1987), during which three tracer tests were conducted: two with irradiated bromide and one with para-toluene sulfonic acid (p-TSA), an organic compound which is more thermally stable than Na-F but much slower and more difficult to analyze.

Thereafter followed a long hiatus in flow and tracer test operations. In late 1991 and early 1992, four brief tests of the reservoir were undertaken to test equipment for the Long-Term Flow Test (LTFT) to follow. A Na-F tracer test was run during one of these tests, with tracer injected on 12 March 1992. During the first phase of the LTFT, a Na-F tracer test was begun on 18 May 
1992 and a p-TSA tracer test was begun on 7 July 1992. The second phase of the LTFT (February - April 1993) included several tracer tests.

After another hiatus in testing, the Reservoir Verification Flow Tests were conducted in May and June 1995, and a final tracer test was conducted in July 1995. One Na-F tracer test and one pTSA tracer test were conducted during these last two tests to obtain final estimates of the volume of the Phase II reservoir.

In addition to some plots of tracer return curves published in reports, the data from the Phase II tracer tests are located in two places. The earlier Phase II data, from the ICFT (Experiment 2067) through the first phase of the LTFT, are stored in paper files in Bruce Robinson's office at LANL. Bob duTeaux has the later Phase II tracer test data in MS-EXCEL files.

\subsection{Further Analysis of Data}

As mentioned in the previous chapter, a relatively thorough analysis has been made of most of the flow test data from Phase I, and there are indications that the reservoir was growing during the last test (Run Segment 5, including the Stress Unlocking Experiment). This very important result could be investigated further by a combined analysis of flow test, tracer test and seismic data. Five tracer tests were conducted during this last Phase I test.

The tracer tests of the Phase II reservoir have not been fully evaluated, particularly those from the tests after and including the first phase of the LTFT. Again, tracer test analysis would be one of several techniques to be used in fully evaluating the nature of the Phase II reservoir and its possible connection with the shallower, Phase I reservoir. Although some numerical modeling of the Phase II reservoir has been done (mostly using GEOCRACK), tracer testing results could serve to calibrate more advanced models with the ultimate goal of optimizing production and injection in a Fenton Hill-type system.

Furthermore, tracer test data could be used to confirm or refute concepts about the evolution of the Phase II reservoir as it was being tested. For example, it has been proposed that flow became more dispersed through a greater number of paths as testing proceeded, suggesting a selfregulating mechanism which would make short-circuiting unlikely. If true, this is extremely positive news for the future of the EGS program. Confirmation of this concept would be important to future developers of EGS, and further evaluation of tracer test data and results would be useful to that end. 


\section{WELL LOG DATA}

\subsection{Introduction}

Many types of logs were run in the Fenton Hill wells. As in most geothermal evaluations, the temperature logs reveal the most about the reservoir and its capacity to supply heat to a given facility. Temperature logs were run before, during and after many of the operations, to identify the fractures which accepted or produced water, and to determine how temperature changed with production. Pressure logs may have been run, but these have not been emphasized in the available documents. Spinner logs were run in a few cases too, but the responses measured across fractures or sets of fractures were generally subtle, which suggested small differences in flow rates and generally did not allow quantitative estimates of the relative contributions of individual fluid entry or loss points.

Other logs were run to evaluate other aspects of the wells and reservoir. Caliper logs were run before and after hydraulic fracturing operations in an attempt to identify fractures. Gamma ray and resistivity logs were also run for this purpose. Although not a logging technique per se, impression packer runs were made, particularly in Phase I, to get a physical impression of a fracture intersecting the wellbore. Images of the wellbore wall were later obtained with a borehole televiewer developed by LANL, which was successfully deployed once or twice in Phase II.

Another logging technique applied in Phase I was running spontaneous potential (SP) and/or induced potential (IP) logs in a pressurized well while generating a current in another well, or pressurizing one well and running the logs in the other. These experiments were undertaken to identify fractures and thus estimate the hydraulic connectivity between the wells. As far as we know, this technique has not been used in other geothermal applications.

Gamma ray logs were also run in connection with radioactive tracer $\left({ }^{82} \mathrm{Br}\right.$ and $\left.{ }^{123} \mathrm{I}\right)$ tests of the system; these would detect the presence of radioactivity near the active fractures in the production well.

\subsection{Data of Interest}

The data of interest from well logging operations include the following:

- the lithology and petrology of the logged interval

- temperature logs run before and after a hydraulic fracturing operation

- impression packer results after a fracturing job

- temperature logs run in the production and injection well before, during and after flow tests

- caliper, resistivity and gamma ray logs run through the production or injection interval 
- resistivity logs run through the production or injection interval

- SP and IP logs, and information on current sources (if a current was generated)

- gamma ray logs run in the production well during radioactive tracer tests

\subsection{Experiments of Interest and Location of Data}

\subsubsection{Phase I}

As discussed in Chapter 2, lithologic and petrologic information from the Phase I wells is included in a paper by Laughlin et al. (1982) and the LANL reports cited therein.

The remaining data of interest would have been generated in nearly all of the early Phase I operations listed in table 1.1 except for the acoustic ranging and shear shadowing experiments. A full set of logs run by outside contractors is stored at the Fenton Hill site. Logs made with LANL tools during the earliest experiments (those without experiment numbers in table 1.1) would probably be found only in Bob Potter's office. The log data from the later Phase I experiments are sometimes stored as plots in the experiment write-ups in the experiment files; some of these plots were reproduced for various LANL reports. In addition, Bob Potter may have data listings and plots in his office. Impression packer results have been reported in an anecdotal way in LANL publications; the drilling records stored at Fenton Hill are another potential source of data. The SP and IP logs would be stored at the site. The gamma ray logs run during the Run Segment $5{ }^{82} \mathrm{Br}$ tracer tests are stored in the experiment files or in Bob Potter's office; some of these are also stored by Zora Dash on the Unix system.

\subsubsection{Phase II}

Geologic data from the original Phase II wells (EE-2 and EE-3) are included in Laughlin et al. (see Chapter 2 for complete reference), and detailed data from EE-2A and EE-3A are presented in an unpublished report by LANL geologist Schoen Levy.

Zora Dash has most of the Phase II temperature logs and some of the gamma ray logs collected from 1980 to 1992 on the Unix system; Bob DuTeaux has the remaining Phase II temperature logs (as MS-EXCEL files on a PC). We found no indication that impression packer runs were made during Phase II. As in Phase I, a complete set of all of logs (including caliper and resistivity logs) run by outside contractors in the Phase II wells is stored at the Fenton Hill site in the well files.

\subsection{Further Analysis of Data}

Additional evaluation of well log data would probably be needed to support any revision to the conceptual models of the Phase I and Phase II reservoirs at Fenton Hill, as was discussed in the two preceding chapters. Obviously, correlation of wellbore features with reservoir characteristics is a key part of that process. Developing a full set of geologic logs for the four wells of interest (GT-2B, EE-1, EE-2A and EE-3A) would be a useful starting point for further 
analysis of other logs. Completion and publication of Schoen Levy's work would be very useful in this regard; Schoen has indicated that a relatively modest amount of time would be required to finish this.

Further interpretation of well logs would also be needed to develop a coupled wellbore and reservoir model of the Fenton Hill system. As discussed in Chapter 4, this type of work would be useful for simulations of energy recovery at various operating pressures.

A detailed evaluation of the Fenton Hill logs could also be used to identify the shortcomings in standard types of logs and/or tools for problems specific to the development and assessment of EGS. For example, although the overall flow rate and temperature of a producing interval can be determined, temperature and spinner logs may be too imprecise and the interval of measurement too coarse to identify individual fractures. Gamma ray tools may need similar modification to enable precise measurements of radioactive tracer returns. 


\section{CONCLUSIONS}

Each of the preceding five chapters has concluded with a short discussion that considers further data analysis that could be undertaken to better understand the Fenton Hill HDR reservoirs and the results of the various experiments undertaken during the project. As discussed in Chapter 1, this may be different from the work that should be done, considering that the goal is to assist the geothermal industry and promote future EGS development. With respect to this question, we offer the following.

\subsection{Hydraulic Fracturing Data}

A logical step in transferring the findings of the Fenton Hill project to interested stakeholders would be to index and archive the hydraulic fracturing experience, data and results. Details are discussed in section 2.4. Following this, an experienced hydraulic fracturing specialist and a rock mechanics specialist would undertake a review of these data, the existing well log and seismic results, and the existing fracturing data analyses, to evaluate certain relevant questions. These include how and whether the state of stress changed during sequential fracturing jobs, how the orientation of fractures changed with depth and location, and how the reservoir grew as operations proceeded.

\subsection{Seismic Data}

It appears warranted that some effort be made to organize, catalog and store some of the existing seismic data in a single location and format and on media that are likely to have long-term stability. Given the mixed opinions about the quality and value of further analysis of Phase I seismic data (see section 3.4), this work for Phase I may best be restricted to the data from Experiments 203, 195 and 204 (hydraulic fracturing and flow testing of EE-1; see table 1.1) and the Stress Unlocking Experiment at the end of Run Segment 5 (Experiment 217), which are thought to be good enough to merit re-evaluation using newer techniques.

For Phase II there is a very great quantity of digital data on disks, analog tape and digital tape, and an effort to store and catalog all of the raw data may exceed patience and reasonable expense. Therefore, it would be best to evaluate the existing seismic history of the project and select those experiments and periods from which data should be kept, simply discarding the rest. The involvement of a seismologist would be required in this effort.

As discussed in section 3.4, any further evaluation of the Phase II seismic data would have to consider certain limitations on data quality and certainty, including the instrument location with respect to basement, calibration techniques, and instrument quality and behavior. In this regard, the hands-on experience of LANL personnel has been crucial to the existing data processing, and much of this experience may not be clearly documented along with the raw data and even with much of the processed data. Therefore, the cataloging effort would need to include interviews with and/or reports written by the original LANL seismologists, to document these limitations and how they have been handled.

The goal of cataloging and storage is to make the data available in the future to test with newer techniques of numerical analysis (see section 3.4), and to integrate the results of all experiments 
to trace the history of reservoir development, approaching the project from a single, consistent point of view. Of particular, but not exclusive, interest would be: a) an evaluation of longperiod events, which were identified after extensive filtering of the data from Experiment 2032; b) review of the hypocentral location data from sequential fracturing jobs conducted in EE-2 and EE-3A with a view toward analyzing the growth of the reservoir; and c) the breakdown behavior of the rock and the growth of the reservoir analyzed using a combination of hydraulic fracturing and seismic studies.

Because several members of the LANL Fenton Hill project staff are participants in EGS seismology projects that are sponsored by the Japanese government (see section 3.4), the activities of these projects should be reviewed fully before any additional evaluation of the Fenton Hill data is contemplated.

In spite of the potential utility of the seismic data, it is our opinion that the suggested reevaluations have a relatively low probability of producing information that will be directly useful for EGS developers and stakeholders, especially considering the cost and effort required. The prime reason for this is that the seismic experience at Fenton Hill may not directly apply elsewhere. On the other hand, specific data sets could be evaluated together with data from other disciplines to investigate fundamental EGS reservoir concepts which may apply at other sites. Furthermore, the Fenton Hill data may be useful for the extension of microseismic data processing and application technologies.

\subsection{Flow Test Data}

Further analysis, particularly with numerical simulation, of the Fenton Hill flow test data could provide a better understanding of the size of the reservoir, its hydraulic properties and its heat transfer characteristics under various operating conditions. This could project long-term behavior and the potential of enhancing production with additional production wells. The results of such analyses would have obvious implications for other developers of EGS. Limitations on modeling are set, however, by the lack of true long-term flow and temperature drawdown during the Phase II tests.

A relatively thorough Phase I flow test analysis has been made in terms of temperature behavior and system impedance, but the physical model of the Phase I reservoir was never brought to complete consensus, and the evidence for reservoir growth during the test was somewhat modelspecific. This important conclusion should be re-investigated with an integrated analysis that includes evaluation of transient pressure data (not yet fully studied) and a new numerical model.

In contrast, the physical model of the Phase II reservoir is in some ways better understood (from seismic data), but there was very little in-depth analysis of the Phase II test data. Some of this evaluation is being done by interested parties outside LANL, particularly to validate numerical models of HDR systems. There is more to be gained from an integrated look at the Phase II system, which should include further study of pressure transient data and long-term leak-off data with respect to the opening pressures of joints (the focus of past investigations) and the pressuredependency of reservoir storage and other hydraulic properties. This work would require extracting data from the DMACS system. 
More focused investigations could concentrate on the following:

- The cyclic flow tests that were conducted at the end of Phase II (May 1993) and during the RVFT (Reservoir Verification Flow Tests; 1995) produced encouraging results in terms of energy recovery. These tests included the sudden drop of system impedance on 6 (or 13?) May 1993, and the continued lower impedance when testing resumed in 1995. As far as we know, these tests have not been evaluated in terms of reservoir engineering and rock mechanics, and the apparent significance of the results should be evaluated in light of these disciplines.

- Numerical modeling to estimate the additional energy recovery that can be expected from having more than one production well per injection well (LANL has done some preliminary work on this). Similarly, a coupled wellbore-reservoir model should be developed to evaluate energy production and well behavior (particularly wellbore heat loss) at various operating pressures and flow rates. For these types of studies, well test data would be used to calibrate a model of the reservoir, thus enabling predictions of future performance to be made under various operating scenarios.

- It has been inferred that a connection was made between the Phase I and Phase II reservoirs at Fenton Hill, either through the reservoir or via the annulus of the injection well. A further evaluation of observation well data and other data (seismic, tracer and well log) may confirm the connection. If so, the mechanism of connection should be evaluated.

- Returns of water to the surface through the annulus were consistently observed during Phase II testing, particularly at higher pressures of injection and production. The origins of these leaks were not well understood, and their potential long-term consequences not known. Because such leaks present the risk of long-term well degradation, and because they reduce production efficiency, they should be more thoroughly evaluated.

With convenient data access, these types of evaluations could be undertaken at reasonable cost.

The Japanese government is sponsoring a program (MURPHY) to evaluate flow test and other data from EGS reservoirs that involves several individuals from LANL. Therefore, it is possible that additional evaluation of Fenton Hill test data is being or will be undertaken under the auspices of that program, and duplication of effort should obviously be avoided.

\section{4 $\underline{\text { Tracer Test Data }}$}

Tracer tests are relatively inexpensive to implement and evaluate, and so can provide good value for cost. A relatively thorough analysis has been made of most of the Phase I data, which include evidence of growth during a flow test that included five tracer tests (see section 5.4). This important result could be investigated further by combining an analysis of flow test, tracer test and seismic data. 
The tracer tests of the Phase II reservoir have not been fully evaluated, particularly those from the tests during and after the first phase of the LTFT. Tracer test analysis could be used in a full evaluation of the Phase II reservoir and its possible connection with the shallower, Phase I reservoir. Although some numerical modeling of the Phase II reservoir has been done (mostly using GEOCRACK), tracer test results may serve to calibrate a more advanced model with the ultimate goal of theoretically optimizing production and injection in a Fenton Hill-type system. There will be limitations to tracer-based calibrations because the system geometry can never be uniquely established, and long-term tracer return data are generally not available (tests were often terminated before tracer levels had stabilized).

Furthermore, an effort could be made to determine whether tracer test data can confirm or refute concepts about the evolution of the Phase II reservoir as it was being tested. For example, it has been proposed that flow became more dispersed through a greater number of paths as testing proceeded, suggesting a self-regulating mechanism which would make short-circuiting unlikely. If true, this is extremely positive news for the future of the EGS program. Confirmation of this concept would be important to future developers of EGS, and further evaluation of tracer test data and results would be useful to that end.

\subsection{Well Log Data}

Evaluation of well log data may be needed to support revisions to the conceptual models of the Phase I and Phase II reservoirs that are discussed above. If so, developing a full set of geologic logs for the four wells of interest (GT-2B, EE-1, EE-2A and EE-3A) would be a useful starting point (this work is partially complete, see section 6.4). Further interpretation of logs may also assist the development of a coupled wellbore and reservoir model. As discussed in Chapter 4, this type of work would be useful for simulations of energy recovery at various operating pressures. However, the well log data are highly site-specific, and further compilations or study with respect to the Fenton Hill system itself are warranted only within the context of studies that have a broader EGS objective, as mentioned in section 7.2.

A detailed evaluation might also help to identify the shortcomings in standard types of logs and/or tools for problems specific to the development and assessment of EGS. For example, although the overall flow rate and temperature of a producing interval can be determined, temperature and spinner logs may be too imprecise and the interval of measurement too coarse to identify individual fractures. Gamma ray tools may need similar modification to enable precise measurements of radioactive tracer returns. The desired levels of precision should be evaluated in light of existing experience, and then reviewed by expert(s) on well logging technology, to determine whether improvements are likely to be achieved.

\subsection{Summary}

In undertaking our work on the Fenton Hill project, it became clear that opinions vary widely on the value of extracting further information or undertaking additional analyses. Our approach in this work has been to focus on those aspects of the Fenton Hill experience that have the most obvious potential to be useful to future developers of EGS. For some of the data thus identified, 
we have offered a definite opinion. For others, the value of additional work remains to be evaluated by appropriate specialists in a given field (e.g., rock mechanics).

Indexing and archiving the data is a good first step, and PERI has a task order underway to begin this. Without such an archive, it would be very difficult to make any sort of integrated analysis of Fenton Hill, which is required to extract information relevant to EGS reservoir behavior in general, and particularly for systems developed in crystalline rock. However, difficulties will be encountered in obtaining and storing the data (particularly the seismic data), which will likely result in an incomplete archive. A very strong commitment to the data retrieval process, necessarily involving LANL personnel, will be needed to completely archive the data of interest from Fenton Hill, thus preserving it for additional evaluation.

Beyond these tasks, further studies of the Fenton Hill Project data should be carried out in the context of answering two general questions that relate to hypothetical future EGS projects in low-permeability reservoirs. The objectives of such projects would be relatively simple: to drill into hot but (relatively) impermeable rock, fracture the rock to achieve hydraulic communication between wells, and produce energy at the surface at commercially viable rates.

The first question that follows is: what part of the Fenton Hill data and experience could be used to reduce the cost of EGS development? It is obvious that a large reduction of cost would result from drilling one well, fracturing it, mapping the fractures using seismic techniques, then drilling the second well into the rock volume that was found to be seismically active. This leads to asking: a) given the history of hydraulic fracturing, is there a relatively simple set of fracturing operations that is most likely to be successful; b) what are the required operations (equipment, pressures, volumes, well completions); and c) what is the minimum seismic array needed, how should the data be collected, and what analyses of seismic data will yield the required definition? If downhole geophones are essential, the drilling and emplacement cost will not be insignificant unless pre-existing wells are available.

It follows that the Fenton Hill hydraulic fracturing and seismic data should be reviewed to extract a set of experiences that would serve as type examples for future operations, showing how the results of these experiences can be evaluated, showing how they relate to planning and executing a cost-effective project, and illustrating risks and uncertainties.

The second question that follows is: what unresolved questions could be partially or fully resolved by further evaluation of the Fenton Hill data? This leads to asking questions related to long-term energy recovery from the system: a) what would the temperature drawdown have been during long-term flow; b) would cyclic production schemes enhance long-term energy recovery, and; c) would multiple production wells tied to a single injector produce higher overall energy production efficiency?

These questions can only be resolved by numerically modeling the existing data with an appropriate numerical simulator, fully calibrated against existing test data. Although such models would undoubtedly include a fair amount of conjecture, they should at least be able to define the limits to development, and the results would suggest various methods of optimizing production under a given set of operational constraints. 
Finally, it should be pointed out that because of budget limitations, a complete search of the numerous (over 500) publications on Fenton Hill to determine if any of the suggested analyses has already been done was necessarily beyond the scope of this work. By interviewing LANL personnel, obtaining important documents, and preparing the Peer Review, we were able to document the major accomplishments of the project. However, it is possible that we did not review some analyses, particularly of the later Phase II flow test data. Therefore, a complete literature search should be made before undertaking any further analysis to avoid duplication of effort. 
Table 1.1: Summary of Important Experiments, Fenton Hill Hot Dry Rock Project

\begin{tabular}{|c|c|c|c|c|}
\hline Item & Well (s) & Date & $\begin{array}{l}\text { Exp. } \\
\text { No. }\end{array}$ & Description of Operation \\
\hline 1 & GT-1 & Mar 73 & $?$ & $\begin{array}{l}\text { Hydraulic fracturing in the interval between 2,429 } \\
\text { and 2,547 feet }\end{array}$ \\
\hline 2 & $\begin{array}{l}\text { GT-2 }(\mathrm{OH}) \\
\text { (TD 6,352 feet) }\end{array}$ & Aug - Sep 74 & $?$ & $\begin{array}{l}\text { Hydraulic fracturing in three intervals: 1) 2,775 - } \\
\text { 2,865 feet; 2) 4,877 - 4,927 feet; and 3) 5,314 - } \\
\text { 5,394 feet }\end{array}$ \\
\hline 3 & $\begin{array}{l}\text { GT-2 (OH) } \\
\text { (TD 6,700 feet) }\end{array}$ & Oct 74 & $?$ & $\begin{array}{l}\text { Hydraulic fracturing between 6,506 and 6,700 feet } \\
\text { through PBR and cemented in liner (6,296 - 6,506 } \\
\text { feet) }\end{array}$ \\
\hline 4 & $\begin{array}{l}\text { GT-2 }(\mathrm{OH}) \\
\text { (TD 6,700 feet) }\end{array}$ & Oct 74 & $?$ & $\begin{array}{l}\text { Hydraulic fracturing through perforations in } \\
\text { cemented liner from 6,370 - 6.380 feet }\end{array}$ \\
\hline 5 & $\begin{array}{l}\text { GT-2 (OH) } \\
\text { (TD 9,619 feet) }\end{array}$ & Dec 74? & $?$ & $\begin{array}{l}\text { Injection fall-off test in deepened well (cemented } \\
\text { liner 8,973 - 9,581 feet; casing packer at 9,212 feet); } \\
\text { fractures unintentionally created below liner }\end{array}$ \\
\hline 6 & $\begin{array}{l}\text { GT-2 }(\mathrm{OH}) \\
\text { (TD 9,619 feet) }\end{array}$ & Jul - Aug 75 & $?$ & $\begin{array}{l}\text { Hydraulic fracturing through perforations at 9,150 - } \\
9,550 \text { feet (five zones were perforated and fractured; } \\
\text { then the zones at 9,450 and 9,550 feet were re- } \\
\text { perforated and fractured again) }\end{array}$ \\
\hline 7 & $\begin{array}{l}\text { EE-1 } \\
\text { (TD 6,886 feet) }\end{array}$ & Aug 75 & $?$ & $\begin{array}{l}\text { Hydraulic fracturing below the bottom of the } 10 \text { - } \\
\text { 3/4-inch casing at } 6,420 \text { feet, first with open-hole } \\
\text { packer set at } 6,480 \text { feet and then with a cement plug } \\
\text { in place from } 6,480 \text { feet to TD }\end{array}$ \\
\hline 8 & $\begin{array}{l}\text { GT-2 and EE-1 } \\
\text { (TD 6,886 feet) }\end{array}$ & Aug 75 & $?$ & $\begin{array}{l}\text { Self-potential and induced-potential logs run in EE- } \\
1 \text { before and during hydraulic fracturing, with the } \\
\text { well pressurized at various levels, and in GT-2 with } \\
\text { a current generated at } 6,450 \text { feet in EE-1 }\end{array}$ \\
\hline 9 & $\begin{array}{l}\text { EE-1 } \\
\text { (TD 6,886 feet) }\end{array}$ & Aug 75 & $?$ & $\begin{array}{l}\text { Acoustic ranging experiment (charges detonated in } \\
\text { EE-1 at 6,200, 6,400, 6,600 and 6,800 feet and } \\
\text { signals recorded by geophones in GT-2 at similar } \\
\text { depths) }\end{array}$ \\
\hline 10 & $\begin{array}{l}\text { EE-1 } \\
\text { (TD 9,100 feet) }\end{array}$ & 1 Sep 75 & $?$ & $\begin{array}{l}\text { Acoustic ranging experiment ( } 3 \text { charges detonated in } \\
\text { GT-2; signals recorded by geophones at 9,087 feet } \\
\text { in EE-1) }\end{array}$ \\
\hline
\end{tabular}


Table 1.1: Summary of Important Experiments, Fenton Hill Hot Dry Rock Project

\begin{tabular}{|c|c|c|c|c|}
\hline Item & Well (s) & Date & $\begin{array}{l}\text { Exp. } \\
\text { No. }\end{array}$ & Description of Operation \\
\hline 11 & $\begin{array}{l}\text { EE-1 } \\
\text { (TD 9,575 feet) }\end{array}$ & Sep 75 & $?$ & $\begin{array}{l}\text { Acoustic ranging experiment (charges detonated at } \\
\text { 9,531 and 9,581 feet in GT-2; signal recorded by } \\
\text { geophones at 9,565 feet in EE-1) }\end{array}$ \\
\hline 12 & $\begin{array}{l}\text { EE-1 } \\
\text { (TD 9,575 feet) }\end{array}$ & Sep 75 & $?$ & $\begin{array}{l}\text { Repeat of acoustic ranging experiment (charges } \\
\text { detonated at 9,535 and 9,513 feet in GT-2; signal } \\
\text { recorded by geophones at 9,558 feet in EE-1) }\end{array}$ \\
\hline 13 & GT-2 & 20 Sep 75 & $?$ & Extension of fracture in GT-2 \\
\hline 14 & $\begin{array}{l}\text { EE-1 } \\
\text { (TD 9,575 feet?) }\end{array}$ & 20 Sep 75 & ? & $\begin{array}{l}\text { Self-potential and induced-potential logs in EE-1 } \\
\text { while extending fracture in GT-2 }\end{array}$ \\
\hline 15 & $\begin{array}{l}\text { EE-1 } \\
\text { (TD 9,877 feet) }\end{array}$ & 30 Sep 75 & ? & $\begin{array}{l}\text { Pressurization of GT-2 (at maximum rates and } \\
\text { pressures of } 155 \text { gpm and 2,250 psi) generates } \\
\text { seismic signals recorded in EE-1 by geophones at } \\
9,575 \text { feet }\end{array}$ \\
\hline 16 & $\begin{array}{l}\text { EE-1 } \\
\text { (TD 9,877 feet) }\end{array}$ & 5 Oct 75 & $?$ & $\begin{array}{l}\text { Pressurization of GT-2 (at } 168 \text { gpm and maximum } \\
\text { pressure of 2,150 psi) generates seismic signals } \\
\text { recorded in EE-1 by geophones at 9,211, 9,409, } \\
9656 \text { and 9,856 feet }\end{array}$ \\
\hline 17 & $\begin{array}{l}\text { EE-1 } \\
\text { (TD 10,053 feet) }\end{array}$ & 14 Oct 75 & ? & $\begin{array}{l}\text { Hydraulic fracturing in EE-1 below open hole } \\
\text { packer set at 9,600 feet }\end{array}$ \\
\hline 18 & $\begin{array}{l}\text { GT-2 and EE-1 } \\
\text { (TD } 10,053 \text { feet) }\end{array}$ & 3 - 5 Mar 76 & 117 & $\begin{array}{l}\text { Mapping of EE-1 fractures by injecting into EE-1 at } \\
168 \text { gpm and recording seismic signals in GT-2 }\end{array}$ \\
\hline 19 & GT-2 and EE-1 & 23 and 24 Mar 76 & 115 & Tracer test using Na-F (sodium fluorescein) \\
\hline 20 & GT-2 and EE-1 & 6 May 76 & 122 & $\begin{array}{l}\text { Mapping of EE-1 fractures by injecting into EE-1 at } \\
168 \text { gpm and recording seismic signals at three } \\
\text { depths in GT-2 }\end{array}$ \\
\hline 21 & GT-2 and EE-1 & 27 May 76 & 126 & $\begin{array}{l}\text { "Wallbanger" used to generate signals in EE-1 at } \\
\text { 9,442 feet and recording signals in GT-2 at nine } \\
\text { depths between 9,412 and 9,482 feet }\end{array}$ \\
\hline 22 & GT-2 and EE-1 & 16 Jun 76 & 127 & $\begin{array}{l}\text { Wallbanger used to generate signals in EE-2 which } \\
\text { were recorded in GT-2; this was done at a series of } \\
\text { equivalent depths in both wells }\end{array}$ \\
\hline
\end{tabular}


Table 1.1: Summary of Important Experiments, Fenton Hill Hot Dry Rock Project

\begin{tabular}{|c|c|c|c|c|}
\hline Item & Well (s) & Date & $\begin{array}{l}\text { Exp. } \\
\text { No. }\end{array}$ & Description of Operation \\
\hline 23 & GT-2 and EE-1 & 22 - 29 Jun 76 & $\begin{array}{l}\text { 129A; } \\
129 B\end{array}$ & $\begin{array}{l}\text { Fracture mapping while injecting at } 170 \mathrm{gpm} \text { in EE- } \\
1 \text { and recording seismic signals at 9,610, 9,630, } \\
9,133 \text { and 9,025 feet in GT-2 }\end{array}$ \\
\hline 24 & GT-2 and EE-1 & 14 Oct 76 & 145 & $\begin{array}{l}\text { Acoustic ranging experiment to improve } \\
\text { measurements of seismic velocity - charges fired at } \\
8,481,8,600,8,719,8,845,8,964 \text { and } 9083 \text { feet in } \\
\text { EE-1; signals recorded in GT-2 }\end{array}$ \\
\hline 25 & GT-2 and EE-1 & 27 Oct 76 & 146 & $\begin{array}{l}\text { Acoustic ranging experiment to confirm P-wave } \\
\text { travel times - charges fired at 8,481, 8,600, 8,719, } \\
8,845,8,964 \text { and } 9083 \text { feet in EE-1; signals recorded } \\
\text { in GT-2 }\end{array}$ \\
\hline 26 & GT-2 and EE-1 & 1 - 11 Nov 1976 & 137 & $\begin{array}{l}\text { Flow and tracer test of Phase I "First Reservoir" } \\
\text { prior to silica leaching experiment }\end{array}$ \\
\hline 27 & GT-2 and EE-1 & 12 - 13 Jan 77 & 150 & $\begin{array}{l}\text { Acoustic ranging experiment using large, modified } \\
\text { geophone package in EE-1 to record signals from } \\
\text { charges detonated in GT-2 }\end{array}$ \\
\hline 28 & GT-2 and EE-1 & 8 Mar 77 & 159 & $\begin{array}{l}\text { Shear-shadowing experiment: with the wells } \\
\text { pressurized and static, charges detonated in EE- } 1 \text { at } \\
9,038 \text { feet and signals recorded in GT-2 at } 9,045 \text { feet } \\
\text { to get additional data on the geometry of the fracture } \\
\text { system to help plan redrill of GT-2 }\end{array}$ \\
\hline 29 & GT-2 and EE-1 & 9 Mar 77 & 159B & $\begin{array}{l}\text { Repeat of shear-shadowing experiment with charges } \\
\text { detonated in EE-1 at 8,487 feet and signals recorded } \\
\text { in GT-2 at 8,544 feet }\end{array}$ \\
\hline 30 & GT-2 and EE-1 & 16 Mar 77 & 160 & $\begin{array}{l}\text { Induced-potential log from 7,400 - 9,100 feet in GT- } \\
2 \text { while current induced in at 9,700 feet in EE-1; } \\
\text { data collected with fracture pressurized and static }\end{array}$ \\
\hline 31 & GT-2 and EE-1 & 21 Mar 77 & 159C & $\begin{array}{l}\text { Repeat of shear-shadowing experiment with charges } \\
\text { detonated in EE-1 at 8,762 feet and signals recorded } \\
\text { in GT-2 at 8,794 feet with fracture pressurized to } \\
1,640 \text { psi }\end{array}$ \\
\hline 32 & GT-2 and EE-1 & 22 Mar 77 & 159D & $\begin{array}{l}\text { Repeat of shear-shadowing experiment with charges } \\
\text { detonated in EE-1 at 8,000 feet and signals recorded } \\
\text { in GT-2 at 8,123 feet }\end{array}$ \\
\hline
\end{tabular}


Table 1.1: Summary of Important Experiments, Fenton Hill Hot Dry Rock Project

\begin{tabular}{|c|c|c|c|c|}
\hline Item & Well (s) & Date & $\begin{array}{l}\text { Exp. } \\
\text { No. }\end{array}$ & Description of Operation \\
\hline 33 & $\begin{array}{l}\text { GT-2B } \\
\text { (TD 8,767 feet) }\end{array}$ & 1 - 3 Jun 77 & 166 & $\begin{array}{l}\text { Hydraulic fracturing (to } 1,830 \mathrm{psi} \text { ) with open hole } \\
\text { packer at 8,706 feet }\end{array}$ \\
\hline 34 & $\begin{array}{l}\text { EE-1 and GT-2B } \\
\text { (TD 8,767 feet) }\end{array}$ & 16 Jun 77 & 170 & $\begin{array}{l}12 \text { hours of injection into EE-1 and production from } \\
\text { GT-2B }\end{array}$ \\
\hline 35 & $\begin{array}{l}\text { EE-1 and GT-2B } \\
\text { (TD 8,907 feet) }\end{array}$ & 8 Aug 77 & $172 \mathrm{~A}$ & Step-pressurization of EE-1 with GT-2B shut in \\
\hline 36 & $\begin{array}{l}\text { EE-1 and GT-2B } \\
\text { (TD 8,907 feet) }\end{array}$ & 18 Aug 77 & $172 \mathrm{C}$ & Step-pressurization of GT-2B with EE-1 shut in \\
\hline 37 & EE-1 and GT-2B & 26 - 30 Sep 77 & 176 & $\begin{array}{l}\text { Run Segment } 1 \text { - four day flow test (injection into } \\
\text { EE-1 and production from GT-2B) }\end{array}$ \\
\hline 38 & EE-1 and GT-2B & $26-28$ Oct 77 & 174 & $\begin{array}{l}\text { Acoustic attenuation (shear-shadowing) experiment } \\
\text { using Dresser Atlas peizoelectric transceivers; wells } \\
\text { pressurized and at hydrostatic conditions }\end{array}$ \\
\hline 39 & EE-1 and GT-2B & 28 Jan - 13 Apr 78 & 176 & $\begin{array}{l}\text { Run Segment } 2 \text { (injection into EE-1 and production } \\
\text { from GT-2B) }\end{array}$ \\
\hline 40 & EE-1 and GT-2B & 8 - 13 Sep 78 & 185 & $\begin{array}{l}\text { Acoustic attenuation (shear-shadowing) experiment } \\
\text { using Dresser Atlas peizoelectric transceivers }\end{array}$ \\
\hline 41 & EE-1 and GT-2B & 18 Sep - 16 Oct 78 & 186 & $\begin{array}{l}\text { Run Segment } 3 \text { (high back-pressure experiment) - } \\
28 \text { day flow test (injection into EE-1 and production } \\
\text { from GT-2B) }\end{array}$ \\
\hline 42 & EE-1 and GT-2B & $23-27$ Oct 78 & 190 & $\begin{array}{l}\text { Low back-pressure impedance measurement after } \\
\text { experiment } 186\end{array}$ \\
\hline 43 & EE-1 & 14 Mar 79 & 203 & $\begin{array}{l}\text { "High flow/high pressure" test of EE-1 (hydraulic } \\
\text { fracturing) at 2,800 psi and } 420 \text { gpm; geophones in } \\
\text { GT-2B at 8,842 feet }\end{array}$ \\
\hline 44 & EE-1 & 21 Mar 79 & 195 & $\begin{array}{l}\text { Massive hydraulic fracturing of EE- } 1 \text { at } 3,000 \text { psi } \\
\text { and } 670 \text { gpm to extend and enlarge fractures created } \\
\text { during Experiment } 203\end{array}$ \\
\hline 45 & EE-1 and GT-2B & 22 Mar 79 & 204 & $\begin{array}{l}\text { Post-MHF flow test (injection into EE-1 and } \\
\text { production from GT-2B) }\end{array}$ \\
\hline
\end{tabular}


Table 1.1: Summary of Important Experiments, Fenton Hill Hot Dry Rock Project

\begin{tabular}{|c|c|c|c|c|}
\hline Item & Well (s) & Date & $\begin{array}{l}\text { Exp. } \\
\text { No. }\end{array}$ & Description of Operation \\
\hline 46 & EE-1 and GT-2B & 23 Oct - 15 Nov 79 & 215 & $\begin{array}{l}\text { Run Segment } 4 \text { (injection into EE-1 and production } \\
\text { from GT-2B) }\end{array}$ \\
\hline 47 & EE-1 and GT-2B & 27 Feb - 8 Dec 80 & 217 & Run Segment 5 (low back-pressure test) \\
\hline 48 & EE-1 and GT-2B & 9 - 10 Dec 80 & $217 ?$ & Stress Unlocking Experiment (SUE) \\
\hline 49 & EE-1 and GT-2B & $11-16$ Dec 80 & $217 ?$ & Post - SUE flow test \\
\hline 50 & EE-2 & 6 Jan 82 & 2003 & $\begin{array}{l}\text { Open hole (no zone isolation) injection test - 2-1/2 } \\
\text { hours }\end{array}$ \\
\hline 51 & EE-3 & 19 Jan 82 & 2006 & Open hole (no zone isolation) injection test - 6 hours \\
\hline 52 & EE-3 & 27 Feb 82 & 2007 & Open hole (no zone isolation) injection test - 6 hours \\
\hline 53 & EE-2 & 30 May 82 & 2011 & $\begin{array}{l}\text { Hydraulic fracturing of EE-2 below bottom of } \\
\text { cemented liner at } 14,698 \text { feet (through PBR set in } \\
\text { liner) at } 280 \mathrm{gpm} / 7000 \mathrm{psi}\end{array}$ \\
\hline 54 & EE-2 & 4 - 5 Jun 82 & 2012 & $\begin{array}{l}\text { Hydraulic fracturing of EE-2 below bottom of } \\
\text { cemented liner at } 14,698 \text { feet (through PBR set in } \\
\text { liner) at 1,000 gpm/6,500 psi }\end{array}$ \\
\hline 55 & EE-2 & 19 - 20 Jun 82 & 2016 & $\begin{array}{l}\text { Hydraulic fracturing of EE-2 below bottom of } \\
\text { cemented liner at 14,698 feet (through PBR set in } \\
\text { liner) at 1,200 gpm/7,000 psi }\end{array}$ \\
\hline 56 & EE-2 & 19 - 20 Jul 82 & 2018 & $\begin{array}{l}\text { Hydraulic fracturing higher up in EE-2 between } \\
\text { casing packer inside the } 9-5 / 8 \text {-inch casing (shoe at } \\
11,587 \text { feet) and top of sand plug at } 12,060 \text { feet; } \\
7,000 \text { psi and } 500 \text { gpm }\end{array}$ \\
\hline 57 & EE-2 & 24 Jul 82 & 2019 & $\begin{array}{l}\text { Hydraulic fracturing higher up in EE-2 between } \\
\text { casing packer inside the } 9-5 / 8 \text {-inch casing (shoe at } \\
11,587 \text { feet) and top of sand plug at } 12,060 \text { feet; no } \\
\text { rate/pressure info reported }\end{array}$ \\
\hline 58 & EE-2 & $6-7$ Oct 82 & 2020 & $\begin{array}{l}\text { Hydraulic fracturing higher up in EE-2 between } \\
\text { casing packer inside the } 9-5 / 8 \text {-inch casing (shoe at } \\
11,587 \text { feet) and top of sand plug at } 12,060 \text { feet; } \\
6,700 \text { psi and 1,400 gpm }\end{array}$ \\
\hline & & & & \\
\hline
\end{tabular}


Table 1.1: Summary of Important Experiments, Fenton Hill Hot Dry Rock Project

\begin{tabular}{|c|c|c|c|c|}
\hline Item & Well (s) & Date & $\begin{array}{l}\text { Exp. } \\
\text { No. }\end{array}$ & Description of Operation \\
\hline 59 & EE-3 & 8 Nov 82 & 2023 & Open hole (no zone isolation) injection test - 6 hours \\
\hline 60 & EE-3 & 13 - 14 Dec 82 & 2025 & $\begin{array}{l}\text { Hydraulic fracturing of EE-3 between bottom of } \\
\text { cemented liner at 11,389 feet (through PBR set in } \\
\text { liner) and top of sand plug at 11,770 feet; } 800 \text { gpm } \\
\text { and 6,500 psi }\end{array}$ \\
\hline 61 & EE-3 & 27 Sep 83 & 2033 & $\begin{array}{l}\text { Hydraulic fracturing of EE-3 between bottom of 9- } \\
\text { 5/8-inch casing at 10,374 feet and top of cemented } \\
\text { liner at 10,950 feet; } 400 \text { gpm and 2,000 psi }\end{array}$ \\
\hline 62 & EE-2 & 6 - 9 Dес 83 & 2032 & $\begin{array}{l}\text { Massive Hydraulic Fracturing in EE-2 between } \\
\text { casing packer at 11,340 feet inside the 9-5/8-inch } \\
\text { casing (shoe at 11,587 feet) and top of sand plug at } \\
11,656 \text { feet; } 7,000 \text { psi and 2,000 gpm; } 5.6 \text { million } \\
\text { gallons injected }\end{array}$ \\
\hline 63 & EE-3 & $\begin{array}{l}31 \text { Jan } 84 \\
4 \text { - } 5 \text { May } 84\end{array}$ & $\begin{array}{l}2037, \\
2039\end{array}$ & $\begin{array}{l}\text { Experiments to investigate the "seismically quiet" } \\
\text { region around EE-3 }\end{array}$ \\
\hline 64 & EE-3 & 15 - 19 May 84 & 2042 & $\begin{array}{l}\text { Massive Hydraulic Fracturing in EE-3 between } \\
\text { casing packer at 11,340 feet inside the 9-5/8-inch } \\
\text { casing (shoe at 11,587 feet) and top of sand plug at } \\
11,656 \text { feet; 7,000 psi and 2,000 gpm; } 5.6 \text { million } \\
\text { gallons injected }\end{array}$ \\
\hline 65 & EE-3 & after Dec 84 & $\begin{array}{l}2043 \\
2044\end{array}$ & $\begin{array}{l}\text { Experiments to study the fractured region around } \\
\text { EE-3 by temperature and radioactive tracer logging } \\
\text { at various pressures }\end{array}$ \\
\hline 66 & -- & 7 Aug 84 & 2048 & $\begin{array}{l}\text { Calibration shot to determine station corrections for } \\
\text { pre-Cambrian seismic network }\end{array}$ \\
\hline 67 & EE-2 & 16 Apr - 1 May 85 & 2052 & $\begin{array}{l}\text { Hydraulic fracturing of EE-2 in the interval 11,575 - } \\
11,647 \text { feet at } 80 \text { gpm and 2,100 psi }\end{array}$ \\
\hline 68 & $\begin{array}{l}\text { EE-2 / EE-3A } \\
\text { (TD 12,205 feet) }\end{array}$ & 27 - 28 May 1985 & 2059 & $\begin{array}{l}\text { Hydraulic fracturing of EE-3A below open-hole } \\
\text { packer set at } 11,500 \text { feet; injection at } 240 \text { - } 430 \text { gpm, } \\
\text { pressures up to } 11,000 \text { psi; EE-2 alternately opened } \\
\text { (produced) and shut in }\end{array}$ \\
\hline 69 & $\begin{array}{l}\text { EE-3A } \\
\text { (TD 13,183 feet) }\end{array}$ & 29 Jun - 2 Jul 85 & 2061 & $\begin{array}{l}\text { Hydraulic fracturing in EE-3A below an open-hole } \\
\text { packer set at } 12,566 \text { feet at } 170 \text { gpm and } 4,800 \text { psi }\end{array}$ \\
\hline
\end{tabular}


Table 1.1: Summary of Important Experiments, Fenton Hill Hot Dry Rock Project

\begin{tabular}{|c|c|c|c|c|}
\hline Item & Well (s) & Date & $\begin{array}{l}\text { Exp. } \\
\text { No. }\end{array}$ & Description of Operation \\
\hline 70 & $\begin{array}{l}\text { EE-3A } \\
\text { (TD 13,183 feet) }\end{array}$ & 18 - 20 Jul 85 & 2062 & $\begin{array}{l}\text { Hydraulic fracturing in EE-3A below an open-hole } \\
\text { packer set at } 11,975 \text { feet at } 170 \text { gpm and 5,500 psi }\end{array}$ \\
\hline 71 & $\begin{array}{l}\text { EE-3A } \\
\text { (TD 13,183 feet) }\end{array}$ & & 2063 & Hydraulic fracturing of EE-3A \\
\hline 72 & $\begin{array}{l}\text { EE-3A } \\
\text { (TD 13,183 feet) }\end{array}$ & 30 Jan - 2 Feb 86 & 2066 & $\begin{array}{l}\text { Hydraulic fracturing in EE-3A below an open-hole } \\
\text { packer set at 12,336 feet at } 315 \text { gpm and 6,800 psi ; } \\
\text { viscous gel injected for part of the time }\end{array}$ \\
\hline 73 & $\begin{array}{l}\text { EE-2 / EE-3A } \\
\text { (TD 13,183 feet) }\end{array}$ & 19 May - 18 Jun 1986 & 2067 & $\begin{array}{l}\text { Initial Closed-Loop Flow Test (ICFT) of EE-2 / EE- } \\
\text { 3A system }\end{array}$ \\
\hline 74 & EE-2 & 24 Sep - 9 Nov 86 & 2068 & $\begin{array}{l}\text { Venting of EE-2 at } 35 \mathrm{gpm} \text { and } 1,800 \mathrm{psi} \text { after } \\
\text { ICFT; } 50-70 \% \text { of water not produced during the } \\
\text { ICFT was recovered }\end{array}$ \\
\hline 75 & EE-3A & 5 - 6 Dec 86 & 2070 & $\begin{array}{l}\text { Injection into EE-3A at } 125 \text { gpm and 2,200 psi to } \\
\text { evaluate post-ICFT pressures }\end{array}$ \\
\hline 76 & -- & Jan 87 on & $\begin{array}{l}2032 \\
\text { and } \\
\text { others } \\
(2061, \\
2066 \\
2067)\end{array}$ & $\begin{array}{l}\text { Re-analysis of seismic data -transfer from analog } \\
\text { tapes to MASSCOMP system; computerized } \\
\text { determination of P/S arrivals enables many more } \\
\text { events to be picked out; 3-point method enables } \\
\text { identification of planar sources }\end{array}$ \\
\hline 77 & EE-2A / EE-3A & 2 - 9 Dec 87 & 2074 & $\begin{array}{l}\text { Six-day flow test with injection into EE-3A and } \\
\text { production from EE-2A }\end{array}$ \\
\hline 78 & EE-2A & 15 Jun 88 & 2076 & $\begin{array}{l}\text { Injection test in EE-2A at pressures ranging from } \\
1,500 \text { to } 4,300 \text { psi and rates from } 40 \text { to } 640 \text { gpm - } \\
\text { conducted to test liner/tie-back integrity, confirm } \\
\text { fracture locations and estimate impedance between } \\
\text { the well and the reservoir }\end{array}$ \\
\hline 79 & EE-3A & $\begin{array}{l}11 \text { - } 18 \text { Oct } 88 ; \\
27 \text { Mar - } 18 \text { Apr } 89 ; \\
1 \text { May } 89 \text { - } 3 \text { Dec } 91\end{array}$ & 2077 & $\begin{array}{l}\text { Reservoir "leak-off" tests, during which reservoir } \\
\text { was pressurized and vented several times to } \\
\text { determine reservoir volume, water loss and water } \\
\text { storage at various pressures }\end{array}$ \\
\hline 80 & EE-2A / EE-3A & $\begin{array}{l}4 \text { - } 7 \text { Dec } 91 ; \\
4 \text { - } 7 \text { Feb } 92 ; \\
2 \text { - } 13 \text { Mar } 92\end{array}$ & -- & Four "preliminary" tests of Phase II system \\
\hline
\end{tabular}


Table 1.1: Summary of Important Experiments, Fenton Hill Hot Dry Rock Project

\begin{tabular}{|c|c|c|c|c|}
\hline Item & Well (s) & Date & $\begin{array}{l}\text { Exp. } \\
\text { No. }\end{array}$ & Description of Operation \\
\hline 81 & EE-2A / EE-3A & 8 Apr - 31 Jul 92 & -- & $\begin{array}{l}\text { First Phase of Long Term Flow Test (LTFT) - } \\
\text { injection into EE-3A and production from EE-2A }\end{array}$ \\
\hline 82 & EE-2A / EE-3A & 20 Aug - 1 Oct 92 & -- & Interim Flow Test \\
\hline 83 & EE-2A / EE-3A & 4 - 16 Dec 92 & -- & 1,800 psi back-pressure test \\
\hline 84 & EE-2A / EE-3A & 18 Dec 92 - 3 Jan 93 & -- & 2,200 psi back pressure test \\
\hline 85 & EE-2A / EE-3A & 22 Feb - 17 Apr 93 & -- & $\begin{array}{l}\text { Second Phase of Long Term Flow Test, including } \\
\text { pressure stimulation test }\end{array}$ \\
\hline 86 & EE-2A / EE-3A & 4 - 6 May 93 & -- & Cyclic flow tests \\
\hline 87 & EE-2A / EE-3A & ?? - 18 May 93 & -- & Post-cyclic flow \\
\hline 88 & EE-2A / EE-3A & 18 May 93 - May 95 & -- & $\begin{array}{l}\text { Long term pressure and temperature monitoring; } \\
\text { pressure maintenance by injection }\end{array}$ \\
\hline 89 & EE-2A / EE-3A & 10 May - 13 Jun 95 & -- & $\begin{array}{l}\text { First Phase of Reservoir Verification Flow Test } \\
\text { (RVFT) }\end{array}$ \\
\hline 90 & EE-2A / EE-3A & $14-29$ Jun 95 & -- & $\begin{array}{l}\text { Second Phase of Reservoir Verification Flow Test } \\
\text { (RVFT) }\end{array}$ \\
\hline 91 & EE-2A / EE-3A & 3 - 9 Jul 95 & -- & Load-following experiment \\
\hline 92 & EE-2A / EE-3A & 11 Jul 95 & -- & Tracer tests \\
\hline
\end{tabular}

